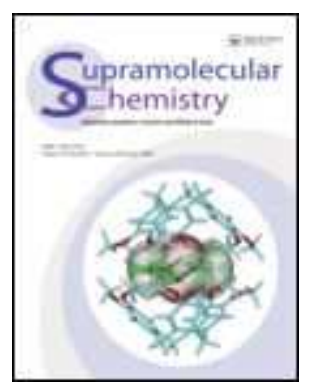

\title{
Bigger, better, faster: Molecular shuttles with sterically non-hindering biisoquinoline chelates
}

\begin{tabular}{|r|l|}
\hline Journal: & Supramolecular Chemistry \\
\hline Manuscript ID: & GSCH-2010-0086.R1 \\
\hline Manuscript Type: & Review \\
\hline Date Submitted by the \\
Author: & 08-Jul-2010 \\
\hline Complete List of Authors: & $\begin{array}{l}\text { Durola, Fabien; Centre de Recherche Paul Pascal } \\
\text { Lux, Jacques; Université de Strasbourg } \\
\text { Sauvage, Jean-Pierre; Université de Strasbourg } \\
\text { Wenger, Oliver; University of Goettingen }\end{array}$ \\
\hline Keywords: & molecular shuttles, copper, biisoquinoline, chelates \\
\hline
\end{tabular}

\section{(s) ScholarONE" \\ Manuscript Central}


We report here the coordination chemistry of a new family of endocyclic but sterically non-hindering bidentate chelates, 8,8'-diaryl-3,3'-biisoquinolines. These ligands allow the construction of fast moving molecular shuttles. $101 \times 73 \mathrm{~mm}(480 \times 480 \mathrm{DPI})$

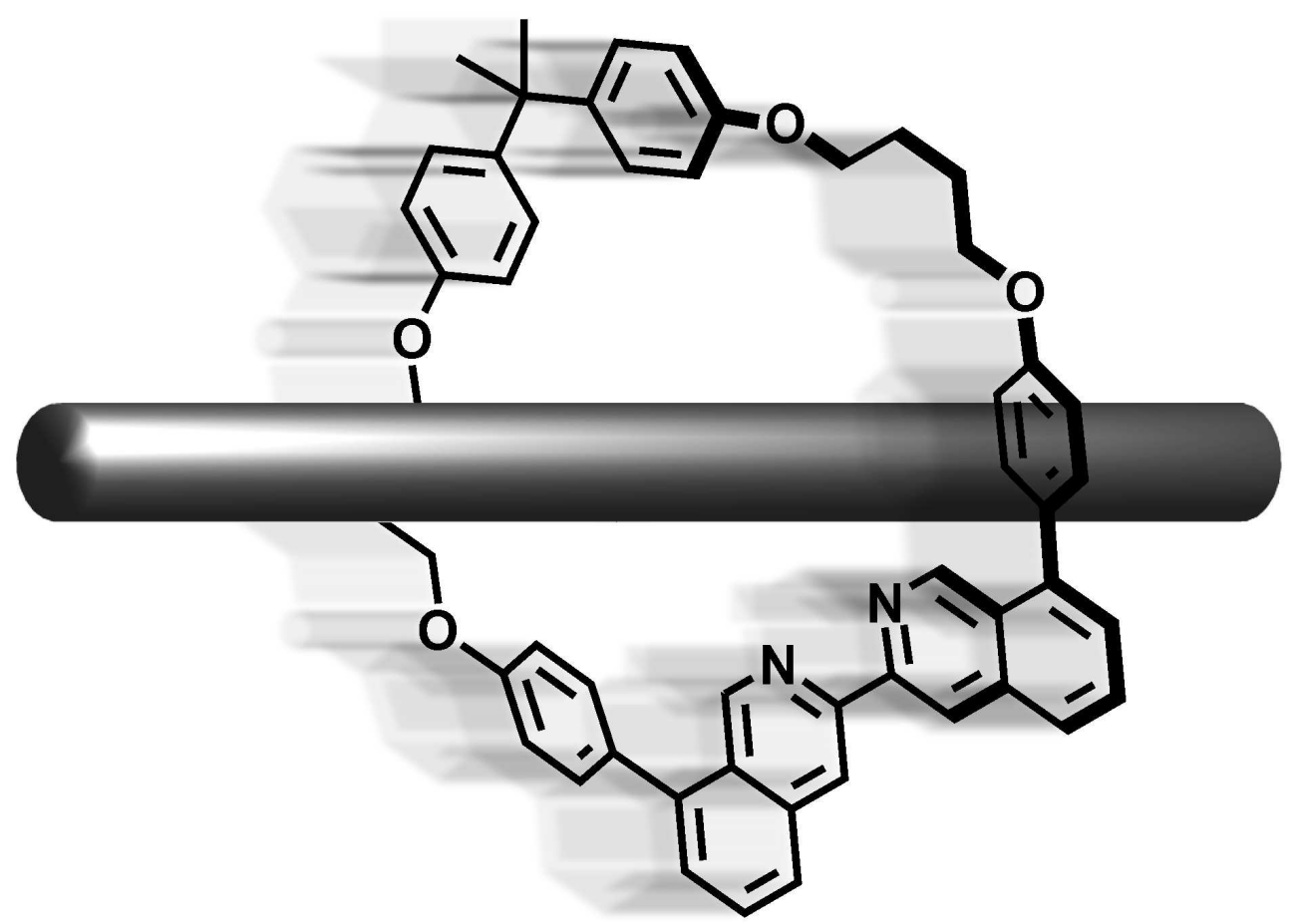




\title{
Bigger, better, faster: Molecular shuttles with sterically non-hindering biisoquinoline chelates
}

Fabien Durola, Jacques Lux, Jean-Pierre Sauvage, and Oliver S. Wenger

\begin{abstract}
In the past, a variety of mechanically interlocked systems such as catenanes and rotaxanes were constructed on the basis of copper(I) coordination chemistry and endocyclic 1,10-phenanthroline ligands. This review reports on the coordination chemistry of a new family of endocyclic bidentate chelators that are sterically non-hindering, namely 8,8'-diaryl-substituted 3,3'-biisoquinolines. These ligands allow the construction of new multi-component assemblies that are inaccessible with the previously investigated 1,10phenanthrolines. On the one hand, the sterically non hindering nature of the new endocyclic chelators makes three-component entanglements around octahedral metal centers such as iron(II), cobalt(II) and ruthenium(II) readily possible. On the other hand, it permits the construction of copper-based molecular shuttles that exhibit shuttling kinetics that excel over those of previously investigated analogous systems with 1,10-phenanthrolines. Thus, within this class of molecular machines, a bigger chelator leads to faster molecular movement, i. e., to a better performance of the molecular machine.
\end{abstract}

\section{Introduction}

The field of molecular machines is vast, and there is a large variety of different ways how mechanically interlocked molecules can be assembled and set into motion. ${ }^{[1-9]}$ One possibility, applied since many years in the Strasbourg group, involves the use of coordination chemistry. ${ }^{[10-15]}$ Indeed, transition metals are particularly well suited for gathering various organic building blocks and disposing them in a given spatial arrangement. Thanks to its well-defined tetrahedral coordination geometry, copper(I) has been particularly useful for the construction of many catenanes and rotaxanes. ${ }^{[16-20]}$ A key ingredient on this route to multicomponent assemblies are bidentate chelators that can be incorporated into a molecular ring in endocyclic fashion. This is the case for example for 2,9-disubstituted 1,10-phenanthroline or 6,6'disubstituted 2,2'-bipyridine. As seen from Scheme 1, the endocyclic coordination mode can only be enforced with these two particular substitution patterns. Any substitution other than in $\alpha$-position to the nitrogen atoms will either lead to a mixture of endocyclic and exocyclic species or to preferred exocyclic coordination. 


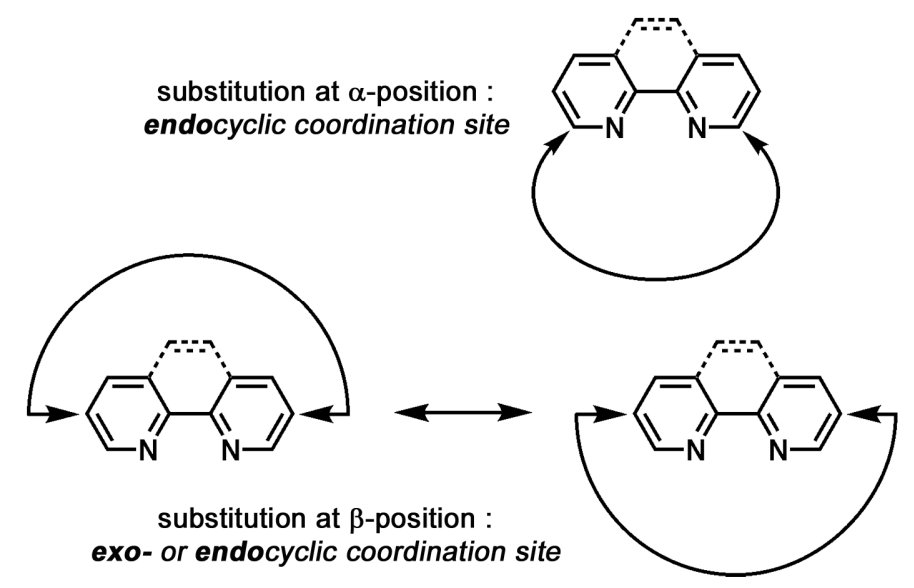

Scheme 1. 2,9-substitution of 1,10-phenanthroline and 6,6'-substitution of 2,2'-bipyridine results in macrocycles with endocyclic coordination. Substitution at other positions is expected to lead to both endoand exocyclic macrocycles.

The 2,9-diphenyl-1,10-phenanthroline (dpp) fragment has played a particularly prominent role due to its extended rigid backbone. This chelator forms very stable $\left[\mathrm{Cu}(\mathrm{dpp})_{2}\right]^{+}$complexes with endocyclic coordination, and mechanically interlocked molecules can be obtained through macrocyclisation via flexible polyethylene glycol chains attached to the dpp-phenyls and subsequent removal of the metal. ${ }^{[21,22]}$ While this approach to obtaining catenanes and rotaxanes has been very successful, it also has its limitations. Firstly, steric constraints impede the formation of complexes in which three dpp fragments gather around a single octahedral metal center: The dpp ligand is simply too small for this purpose. Secondly, molecular shuttles that involve the $\left[\mathrm{Cu}(\mathrm{dpp})_{2}\right]^{+}$fragment exhibit rather slow shuttling kinetics which also has to do with the fact that the dpp ligands are sterically demanding. ${ }^{[13]}$ They shield the copper center too well from the solvent, and this decelerates ligand exchange reactions very significantly. Hence the overall shuttling process, which presumably requires the exchange of one dpp ligand by solvent molecules, is becoming slow.

These two important drawbacks of the dpp ligands have provided the motivation for the search of a new family of bidentate chelators that could be included in macrocycles in an endocyclic but sterically nonhindering fashion. Our search has been successful with the synthesis of 8,8'-disubstituted 3,3'biisoquinolines. ${ }^{[23,24]}$ Here, we review the coordination chemistry of these new ligands on a few selected examples (section 2), and we report on molecular shuttles that are based on the coordination chemistry of these ligands (section 3). 


\section{Coordination chemistry of 8,8 '-disubstituted 3,3 '-biisoquinolines}

As seen from Scheme 2, there are certain analogies between the long-known dpp-ligands and the newly synthesized 8,8'-disubstituted 3,3'-biisoquinolines, but there are also some very important differences. Although both types of ligands are bidentate chelators, the biisoquinolines have no substituents at the $\alpha$-positions to the chelating nitrogen atoms which is in contrast to the dpp molecules. Common to both ligands is the crescent shape, thereby allowing incorporation of each of these ligands in a ring with an endocyclic coordination site, but the 8,8'-diphenyl substituted 3,3'-biisoquinoline fragment (dpbiiq) offers a much more open coordination site than the dpp ligand: The distance between the phenyl rings attached to the 3,3'-biisoquinoline backbone is roughly $11 \AA$, whereas for the 1,10-phenanthroline backbone it is only about $7 \AA .{ }^{[25]}$ Indeed, in the biisoquinoline ligand, the coordinated metal center will be rather remote from the phenyl-rings used to ensure the endocyclic coordination mode.
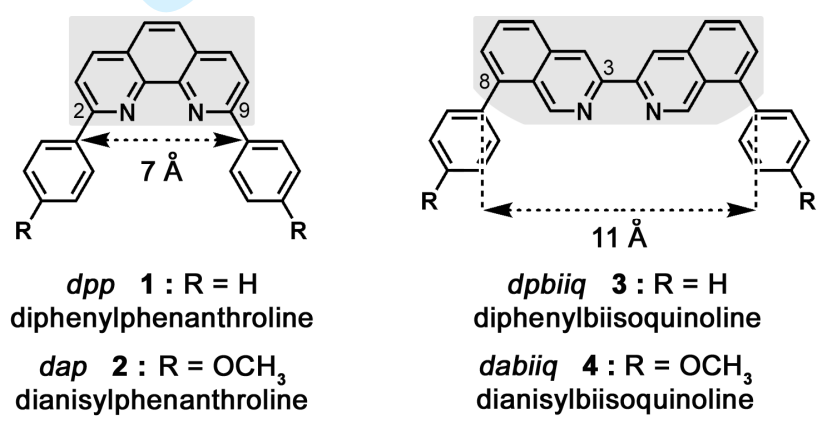

Scheme 2. Endocyclic ligands based on 2,9-diphenyl-1,10-phenanthroline (ddp) and 8,8'-diphenyl-3,3'biisoquinoline (dpbiiq).

The synthesis of the $8,8^{\prime}$-disubstituted biisoquinolines proceeds over several synthetic steps, yet it is possible to produce gram-scale quantities of a variety of molecules of this type in a reasonable amount of time. ${ }^{[24]}$ We explored the synthesis of 3,3'-biisoquinolines that bear phenyl or biphenyl substituents at the 8 and 8' positions, but encountered serious solubility problems with the latter. A key finding is that with these new ligands it is possible to form homoleptic complexes in which three such ligands are coordinated to one single metal center. ${ }^{[26]}$ This is illustrated by Figure 1 which shows the chemical formulas and X-ray crystal structures of a ruthenium(II) complex with three 8,8'-dianisyl-3,3'-biisoquinoline ligands (left) and an iron(II) complex with three 8,8'-diphenylanisyl-3,3'-biisoquinoline ligands (right). 

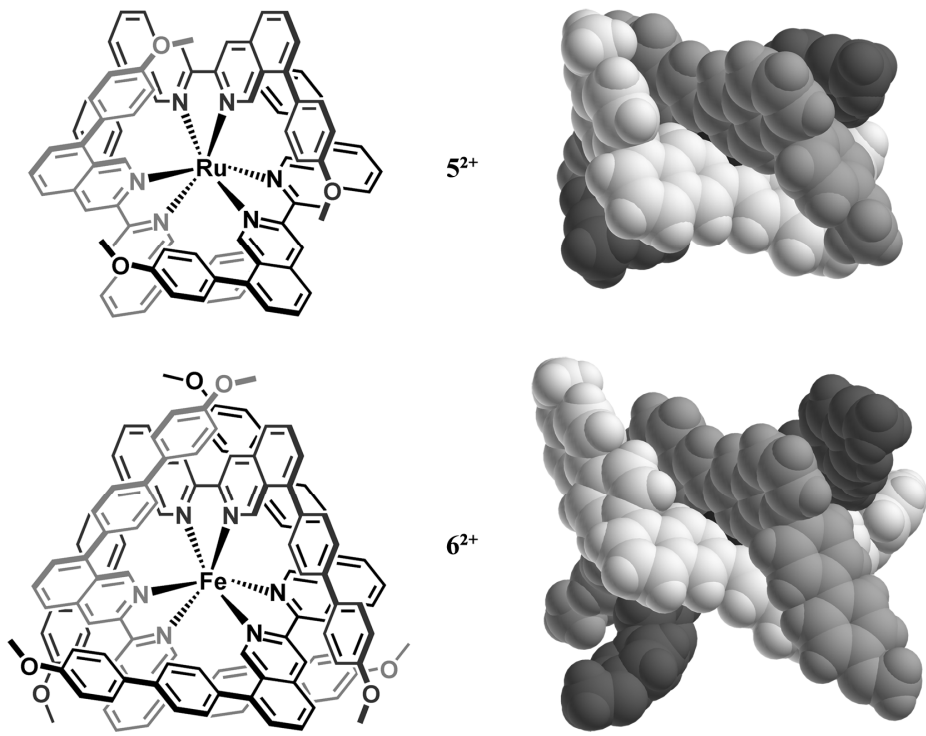

Figure 1. Left: Chemical structures of $\left[\mathrm{Ru}\left(8,8^{\prime} \text {-dianisyl-3,3'-biisoquinoline }\right)_{3}\right]^{2+}$ and $\left[\mathrm{Fe}\left(8,8^{\prime}-\right.\right.$ diphenylanisyl-biisoquinoline $\left.)_{3}\right]^{2+}$. Right: X-ray crystal structures of these complexes. ${ }^{[26]}$

The successful synthesis of the complexes from Figure 1 confirms the initial hypothesis formulated at the outset of this research: Cleary, the new biisoquinoline ligands are sterically non-hindering despite their endocyclic coordination modes. The three-component entanglements of three crescent-shaped chelates coordinated to a single octahedral metal center result in more or less symmetrical helical pseudo- $\mathrm{D}_{3}$ structures. The endotopic cleft distances, i. e., the distances between the oxygen atoms attached to two different anisyls on a given $3,3^{\prime}$-biisoquinoline, range from 15.6 to $16.4 \AA$ in the case of the ruthenium complex with the shorter $8,8^{\prime}$ '-dianisyl-3,3'-biisoquinoline ligand, and from 18.7 to $20.9 \AA$ in the iron(II) complex with the longer 8,8'-diphenylanisyl-3,3'-biisoquinoline ligand. ${ }^{[26,27]}$ These structures are not only aesthetically pleasing, but they also form the basis for multi-component assemblies with new chemical topologies, a branch of research that we have reviewed recently. ${ }^{[28]}$ Here, we intend to focus on the use of the sterically non-hindering ligand family for the construction of new copper-based molecular machines.

\subsection{Fast-moving molecular shuttles based on copper coordination chemistry and biisoquinoline macrocycles}

Molecular shuttles ${ }^{[29-43]}$ constitute a sub-class of molecular machines. Typically, they contain a molecular ring that can glide along an axis on which it has been threaded, whereby the motion can be triggered at will through application of an external stimulus. At least two stations are needed on the molecular axis between which the molecular ring may shuttle back and forth. The approach of the Sauvage group is based on the use of bi- and tri-dentate chelate ligands as stations on the axis, and macrocycles incorporating bidentate ligands 
as gliding rings, whereby the two components are held together by copper(I/II) ions. ${ }^{[13,44-46]}$ The external stimulus triggering the molecular movement is of electrochemical nature: The change in metal oxidation state induces the shuttling motion. The working principle of such a two-station molecular shuttle is illustrated by Scheme 3 .

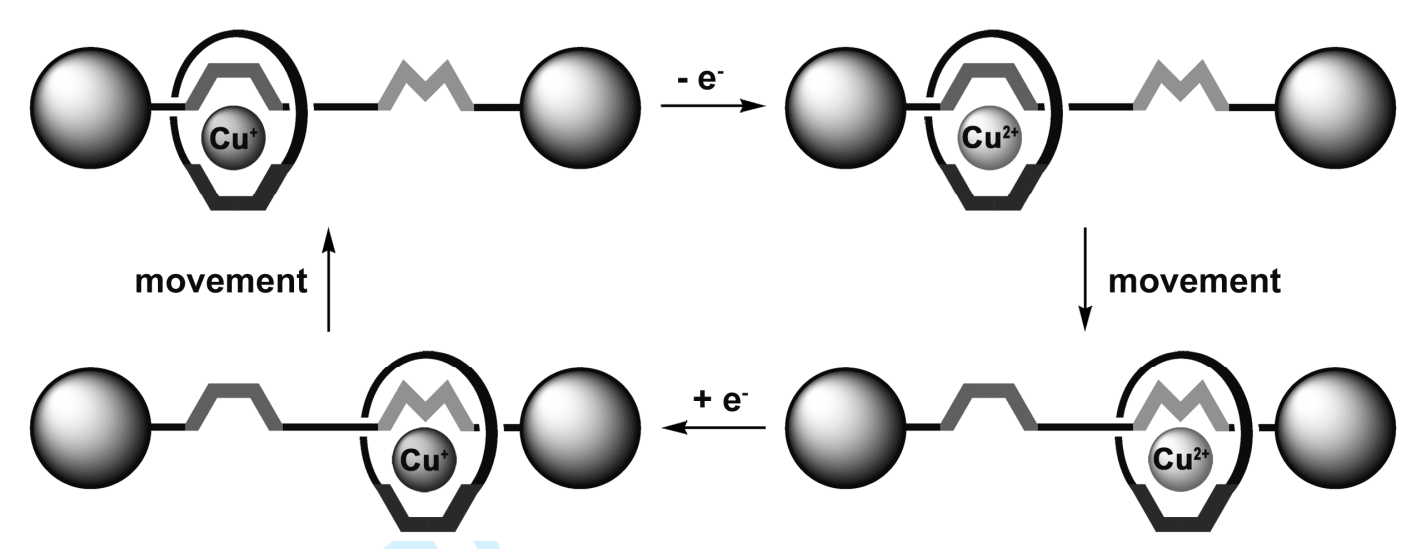

Scheme 3. Working principle of a two-station molecular shuttle comprised of a molecular axis with a bidentate chelate (e. g., a dpp-fragment) and a tridentate ligand (e. g., a terpyridine chelate). The molecular ring is typically a macrocycle incorporating a dpp-fragment.

At the starting point (top left), copper is in its $+\mathrm{I}$ oxidation state for which tetrahedral coordination is thermodynamically preferred, hence the $\mathrm{Cu}(\mathrm{I})$ ion is coordinated to the two bidentate ligands. $\mathrm{Cu}(\mathrm{II})$, by contrast, prefers higher coordination numbers. Therefore, immediately after oxidation (top right), the copper ion finds itself in a thermodynamically unstable coordination environment. The consequence is decoordination of the $\mathrm{Cu}$ (II) ion from the bidentate chelate on the molecular axis and translation of the $\mathrm{Cu}$ (II)macrocycle moiety to the station offering the terdentate ligand (bottom right). Upon reduction of $\mathrm{Cu}(\mathrm{II})$, an unstable five-coordinate $\mathrm{Cu}(\mathrm{I})$ complex will be formed temporarily (bottom left), and this induces the backshuttling of the metal-macrocycle entity to the starting point.

These molecular shuttles are usually true rotaxanes, i. e., there are bulky groups attached to the two ends of the molecular axis, preventing the macrocycle from de-threading. Hence, the shuttling process is usually highly reversible.

Scheme 4 shows a specific example of such a molecular two-station shuttle that was prepared and studied by the Strasbourg group. ${ }^{[13]}$ In this compound, the molecular axis is flexible, which makes it difficult to have a clear view of the geometry and the exact distance between the two stations of the shuttle. Moreover, in the thermodynamically stable tetrahedral copper(I) complex, the metal center is almost completely isolated from the chemical environment: The two sterically demanding 2,9-diphenyl-1,10-phenanthroline (dpp) ligands shield the copper from the solvent. Thus, upon oxidation to $\mathrm{Cu}(\mathrm{II})$, the resulting thermodynamically unstable 
$\left[\mathrm{Cu}(\mathrm{dpp})_{2}\right]^{2+}$ complex stays kinetically inert, because the transient formation of a mobile solvent complex of $\mathrm{Cu}$ (II) is made difficult. As a consequence, the rearrangement of the thermodynamically unstable fourcoordinate species $\mathrm{Cu}_{(4)}$ (II) to the five-coordinate species $\mathrm{Cu}_{(5)}$ (II), i. e. the gliding motion of the copper center plus macrocycle along the molecular axis, takes place only on a minute to hour timescale. ${ }^{[13]}$ The same is true for the reverse process: When $\mathrm{Cu}(\mathrm{II})$ is reduced while being coordinated to the terpyridine station and the macrocyclic dpp-ligand, the resulting five-coordinate species $\mathrm{Cu}_{(5)}(\mathrm{I})$ is also kinetically inert, and the thermodynamically preferred four-coordinate species $\mathrm{Cu}_{(4)}(\mathrm{I})$ is formed equally slowly. In other words, both the forward and backward shuttling kinetics are very slow.

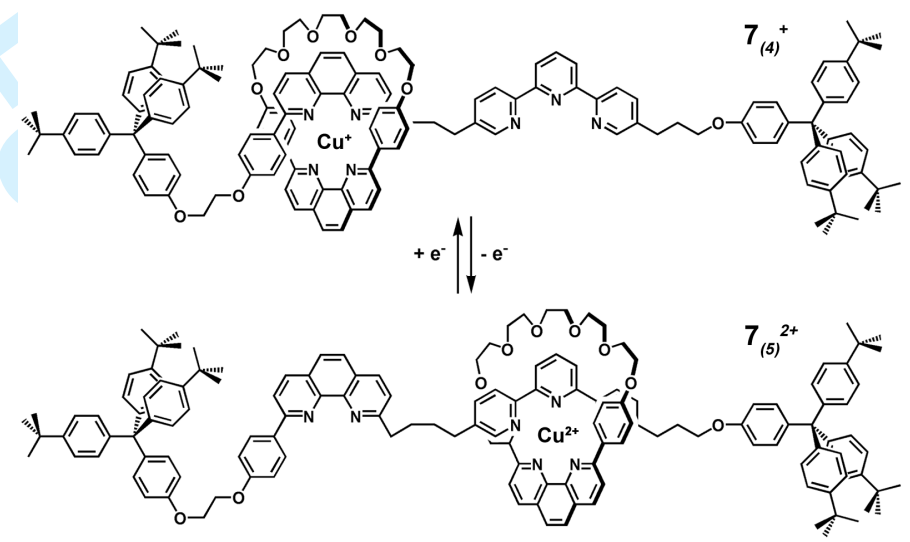

Scheme 4. Two-station molecular shuttle with a relatively flexible molecular axis containing a dpp-station and a terpyridine-station and a 30-membered macrocycle incorporating a dpp chelate.

As shown recently for "pirouetting" copper-complexed rotaxanes, decreasing the steric congestion around the copper coordination center has a strong effect on the rearrangement rates of the complexes. ${ }^{[47]}$ Therefore we reasoned that by using a macrocycle that incorporates the sterically non-hindering dpbiiq fragment 3 instead of the dpp-fragment $\mathbf{1}$, the shuttling kinetics of our molecular machines might be improved. Toward this end, we have prepared macrocycle $\mathbf{8}$ (Scheme 5) which is considerably bigger than the dpp-based macrocycle 9 which was used in the molecular shuttle from Scheme 4. The new macrocycle 8 is 39membered and provides an inner cavity that is about $11 \AA$ wide, whereas the the dpp-based macrocycle 9 is only 30 -membered with an inner cavity of roughly $7 \AA$ width. 

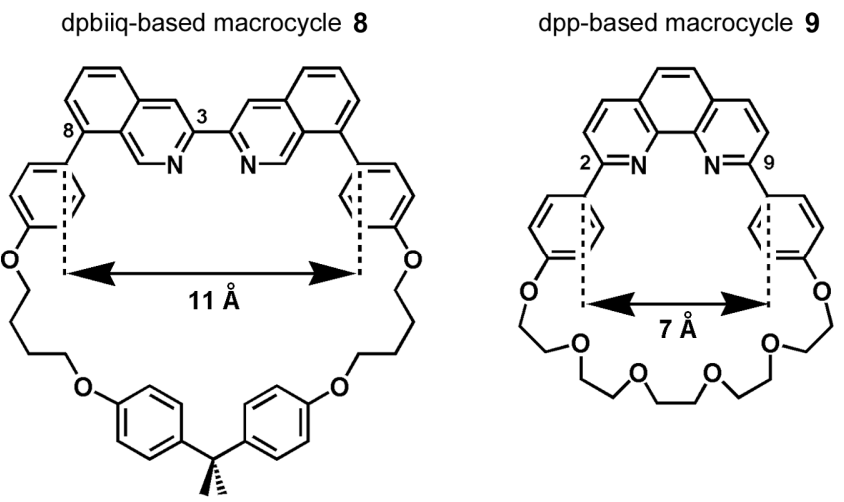

Scheme 5. A 39-membered macrocycle with the dpbiiq ligand motif and a 30-membered macrocycle with the dpp fragment.

We have used the sterically less congesting macrocycle $\mathbf{8}$ as the mobile part in a new molecular shuttle (Scheme 6). In this rotaxane, the molecular axis differs from the previously used axis (Scheme 4) in several respects. The most important difference is that the phenanthroline and the terpyridine stations are now connected via a rigid $p$-phenylene spacer. This makes the new axis significantly less flexible than that of the rotaxane from Scheme 4.
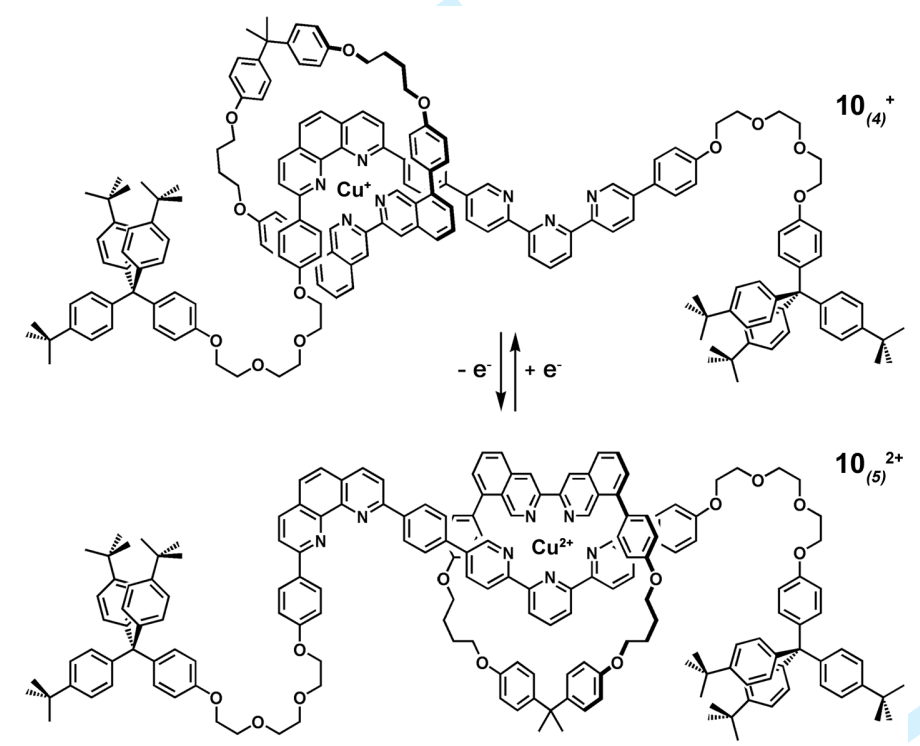

Scheme 6. A copper-based molecular shuttle with a rigid axis and a sterically non-hindering macrocycle.

The electrochemically triggered translation of the copper-complexed ring between the dpp and the terpy stations of the molecular axis was investigated using cyclic voltammetry, by analogy with previously described copper-containing bistable catenanes and rotaxanes ${ }^{[10,11,13]}$. Through variation of the potential scan rate, it is possible to obtain kinetic information on the gliding motion of the macrocycle. ${ }^{[48,49]}$ A few representative cyclic voltammograms (CVs) are shown in Figure 2. 
(a)

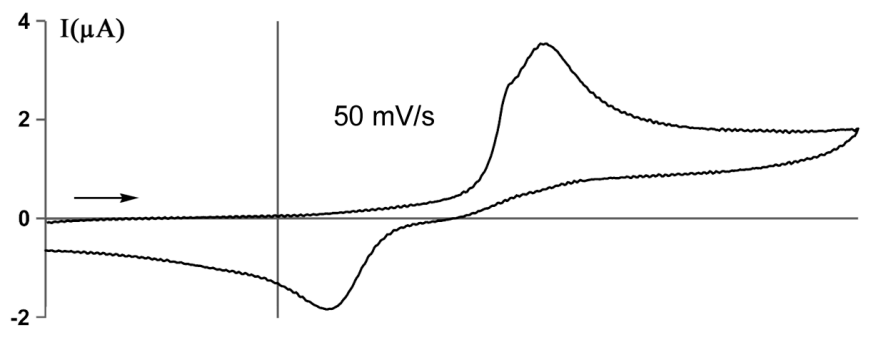

(b)
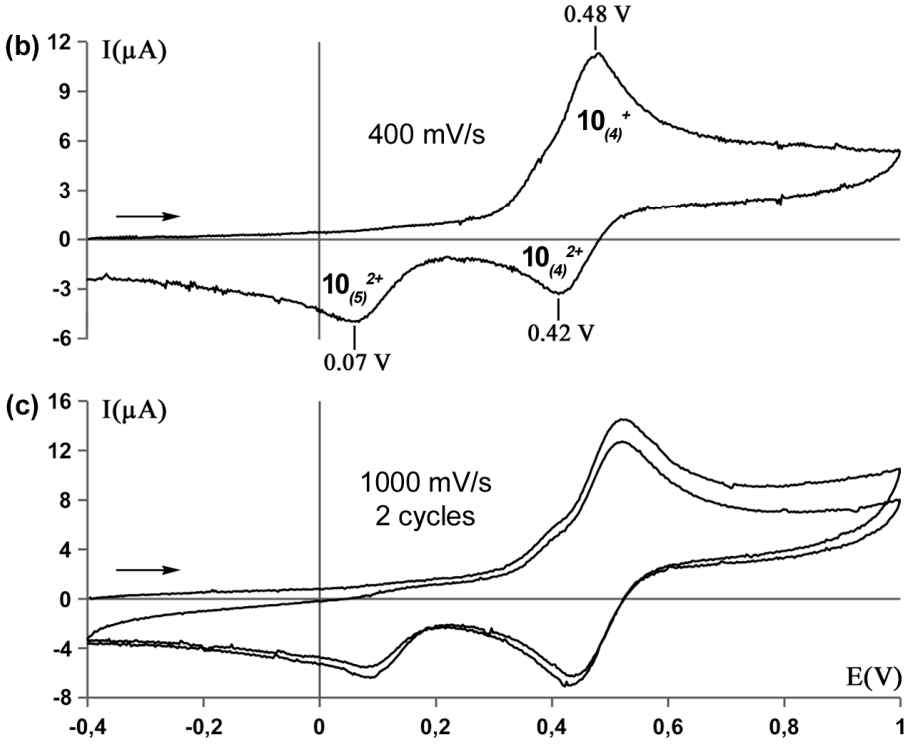

Figure 2. Cyclic voltammograms obtained on the molecular shuttle from Scheme 6 at three different potential scan rates. See reference ${ }^{[45]}$ for experimental details. Potentials are reported versus SCE.

At the starting point of our CV experiments, molecular shuttle $\mathbf{1 0}$ from Scheme 6 has $\mathrm{Cu}(\mathrm{I})$ coordinated to dpp on the axis and dpbiiq on the macrocycle. At all scan rates, we observe only one single wave in the oxidative scan, centered around $0.48 \mathrm{~V}$ vs. SCE. This wave corresponds to oxidation of four-coordinate $\mathrm{Cu}(\mathrm{I})$. In the reductive sweep at low scan rates $(50 \mathrm{mV} / \mathrm{s})$, we observe a wave that is centered around $0.07 \mathrm{~V}$ vs. SCE which is due to reduction of $\mathrm{Cu}$ (II) in five-coordinate environment. This indicates that by the time the reductive sweep begins, the shuttling motion from the bidentate dpp-station to the terdentate terpystation has already taken place. When the scan rate is increased to $400 \mathrm{mV} / \mathrm{s}$, a second reductive wave becomes observable. This wave is centered around $0.42 \mathrm{~V}$ vs. SCE and is attributed to reduction of $\mathrm{Cu}(\mathrm{II})$ in four-coordinate environment. This is a clear indication that under these experimental conditions, some of the molecular shuttles did not have sufficient time to undergo the gliding motion that should have followed $\mathrm{Cu}(\mathrm{I})$ to $\mathrm{Cu}(\mathrm{II})$ conversion in the oxidative sweep. Interestingly, an oxidation wave that could be associated with $\mathrm{Cu}(\mathrm{I})$ oxidation in a five-coordinate environment cannot be observed even at a scan rate of $1000 \mathrm{mV} / \mathrm{s}$. This indicates that the gliding motion from the terpy to the dpp station following $\mathrm{Cu}$ (II) reduction is significantly faster that the reverse gliding motion that follows $\mathrm{Cu}(\mathrm{I})$ oxidation. This finding is in line with previous observations on other molecular machines investigated by the Strasbourg group. ${ }^{[10,13,50-53]}$ 
From these cyclic voltammetry experiments, we extract the following rate constants for the back-and-forth motion of macrocycle $\mathbf{8}$ in molecular shuttle 10:

$$
\begin{aligned}
& \mathrm{10}_{(4)}{ }^{+}-\mathrm{e}^{-} \longrightarrow \mathbf{1 0}_{(4)^{2+}} \longrightarrow \mathrm{Cu}(\mathrm{I}) \text { oxidation } \\
& \mathbf{1 0}_{(4)}{ }^{2+} \longrightarrow \mathbf{1 0}_{(5)^{2+}} \quad \text { gliding, } \mathrm{k}=2 \mathrm{~s}^{-1} \\
& \mathbf{1 0}_{(5)}{ }^{2+}+\mathrm{e}^{-} \longrightarrow \mathbf{1 0}_{(5)}{ }^{+} \quad \mathrm{Cu}(\mathrm{II}) \text { reduction } \\
& \mathbf{1 0}_{(5)}{ }^{+} \longrightarrow \mathbf{1 0}_{(4)}{ }^{+} \quad \text { gliding, } \mathrm{k}>50 \mathrm{~s}^{-1}
\end{aligned}
$$

For comparison, in molecular shuttle 7, the rate constants for the two gliding motions are at least two orders of magnitude lower. It is tempting to attribute this dramatic acceleration fully to the sterically non-hindering nature of the new dpbiiq-based macrocycle, yet it must be noted that shuttles $\mathbf{7}$ and $\mathbf{1 0}$ differ also in the nature of the molecular axis. In shuttle 7, there is a flexible axis with an alkane linker between the two stations, whereas in shuttle $\mathbf{1 0}$ there is a rigid axis with a $p$-phenylene spacer. In order to eliminate any doubts regarding the origin of the improved shuttling kinetics, we have investigated molecular shuttle 11 that is comprised of the same rigid axis as shuttle 10, but with the sterically congesting 30-membered dppbased macrocycle 9 (Scheme 7).

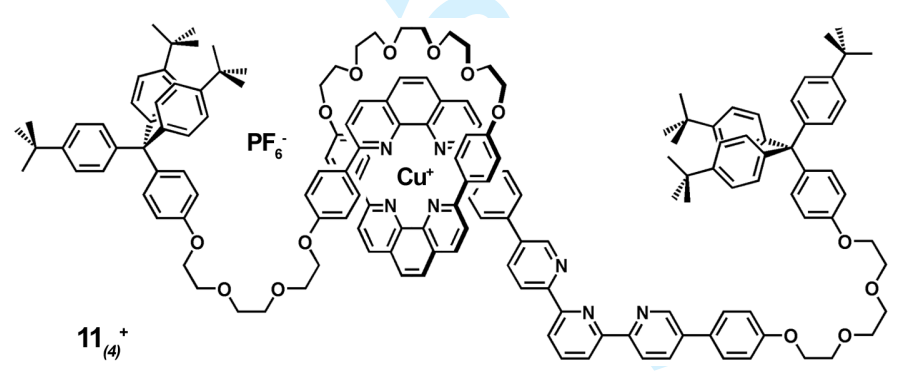

Scheme 7. A molecular shuttle comprised of the same rigid axis as the shuttle from Scheme 6 , but with the smaller macrocycle $\mathbf{9}$ instead of the sterically non-hindering macrocycle $\mathbf{8}$.

The difference in gliding kinetics between shuttles $\mathbf{1 0}$ and $\mathbf{1 1}$ is remarkable. As discussed above, in the shuttle with the biisoquinoline-macrocycle, gliding from the phenanthroline station to the terpyridine station following $\mathrm{Cu}(\mathrm{I})$ oxidation occurs within less than a second. By contrast, after $\mathrm{Cu}(\mathrm{I})$ oxidation of rotaxane 11, the thermodynamically unstable four-coordinate species is stable for several hours. Thus, it is obvious that there exists a pronounced kinetic biisoquinoline effect.

The endocyclic but sterically non-protecting nor hindering nature of dpbiiq is the key to this spectacular improvement. Besides this non hindering character, another important structural difference between dpp and the biisoquinoline ligand is the less rigid nature of the latter. Whereas dpp contains a rigid backbone, the 
biisoquinoline is able to rotate around its $\mathrm{C}_{3}-\mathrm{C}_{3^{\prime}}$ bond, and this may facilitate de-coordination from a metal center through stepwise de-complexation of one nitrogen donor atom after the other.

With these encouraging results at hand, it became realistic to envision molecular shuttles in which the translational motion occurs over a significantly longer distance ${ }^{[44-55]}$ than in the prior systems. This vision included the use of a molecular axis with three instead of only two stations: The end stations should be comprised of the bidentate 1,10-phenanthroline ligand (dpp) to host preferably $\mathrm{Cu}(\mathrm{I})$ and the terdentate terpyridine chelate to host preferably $\mathrm{Cu}$ (II) as in the shuttles from Schemes 6 and 7. The hypothesis was that a 2,2'-bipyridine ligand could serve as an intermediate station that can facilitate the shuttling motion between the two end points. With this ultimate goal in mind, it seemed reasonable to explore in a first step the coordination chemistry and electrochemical behavior of a two-station shuttle containing only a 1,10 phenanthroline (dpp) and a bipyridine (bipy) station. The resulting system, rotaxane $\mathbf{1 2},{ }^{[56]}$ is shown in Scheme 8 .
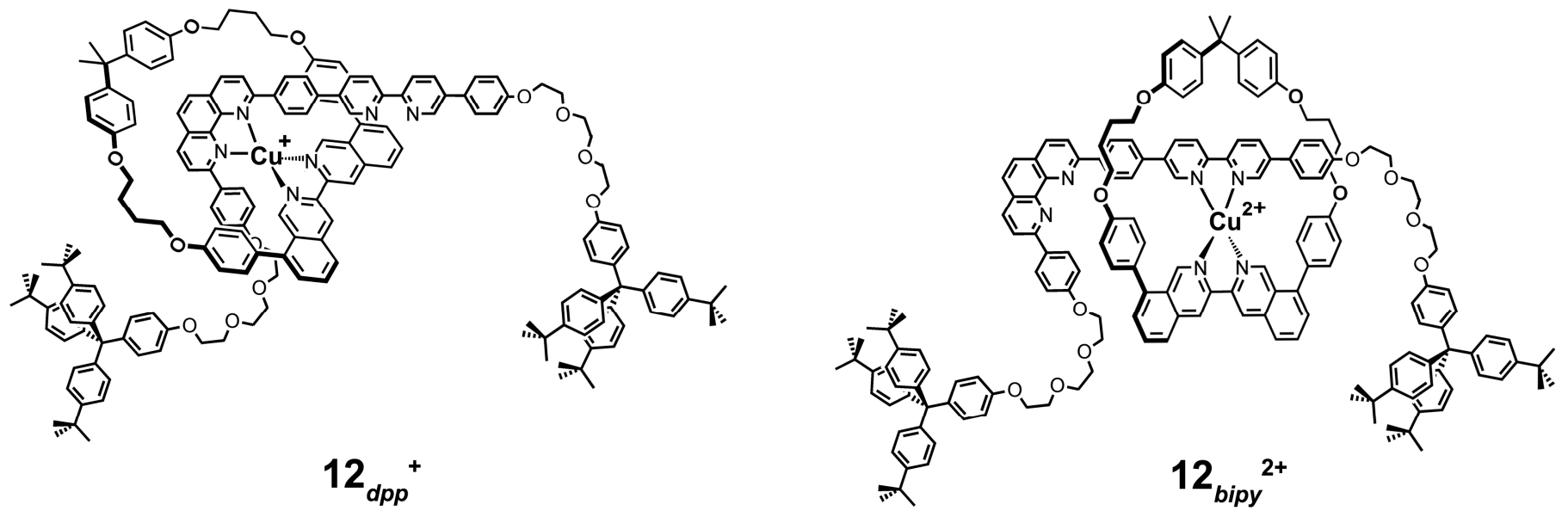

Scheme 8. A phenanthroline-bipyridine two-station shuttle in its two different forms $\mathbf{1 2}_{\text {dpp }}{ }^{+}$and $\mathbf{1 2}_{\text {bipy }}{ }^{2+}$; the subscripts $d p p$ and bipy indicate the position of the mobile ring (macrocycle 8) on the molecular axis.

By contrast to the molecular shuttles previously investigated by the Strasbourg group, ${ }^{[13,44-46]}$ this shuttle contains exclusively bidentate ligands and no terdentate chelates at all. Thus, even $\mathrm{Cu}(\mathrm{II})$ will only achieve a fourfold coordination as far as the nitrogen atoms of the chelates are concerned. However, it should be kept in mind that when the coordination sphere around these chelates is sterically not too demanding, there may be solvent molecules or anions that can coordinate to $\mathrm{Cu}(\mathrm{II})$, thereby satisfying its demand for higher coordination numbers. Indeed, the steric properties of the phenanthroline and bipyridine stations are vastly different: The former is highly shielding and prevents the copper center from interacting with the chemical environment, uptake of solvent molecules or anions as additional ligands is very difficult in this coordination site. The bipyridine station, on the other hand, is sterically much less demanding. Thus, it can be expected that additional ligation of solvent molecules or counterions will stabilize $\mathrm{Cu}(\mathrm{II})$ when coordinated to the 
bipyridine station, thereby making this the thermodynamically preferred station for the metal in its divalent oxidation state.

The relative thermodynamic stabilities between the $\mathrm{Cu}(\mathrm{I})$ and $\mathrm{Cu}(\mathrm{II})$ complexes formed in the molecular shuttle define the driving force for the shuttling motion. Evidently, the thermodynamic stability of $\mathrm{Cu}(\mathrm{II})$ in a bipyridine-biisoquinoline coordination environment (as the case for shuttle 12 of Scheme 8) will differ from the thermodynamic stability of $\mathrm{Cu}$ (II) in a terpyridine-biisoquinoline coordination (as the case for shuttle 10 of Scheme 6). As a consequence, the driving force for the ring-translation in the phenanthrolinebipyridine shuttle will be different from that in the phenanthroline-terpyridine shuttle. This driving force can be estimated from the redox potentials of the various copper complexes. For shuttle 10, the relevant data can be extracted from the cyclic voltammograms in Figure 2: The $[\mathrm{Cu}(\mathrm{dpbiiq})(\mathrm{dpp})]^{+}$complex is oxidized at $0.46 \mathrm{~V}$ vs. SCE, the $\left[\mathrm{Cu}(\mathrm{dpbiiq})(\text { terpy) }]^{2+}\right.$ species is reduced at $0.07 \mathrm{~V}$ vs. SCE. Hence, the driving force $\Delta \mathrm{G}$ for ring translation in the phenanthroline-terpyridine shuttle is roughly $0.39 \mathrm{eV}$. In order to estimate the driving force for the phenanthroline-bipyridine shuttle, the model complexes shown in Scheme 9 were synthesized and investigated electrochemically.

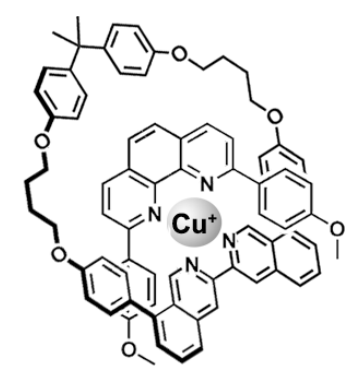

$13_{4}{ }^{2+} / 13_{4}^{+}$ $\mathrm{E}_{1 / 2}=0.34 \mathrm{~V}$ vs SCE
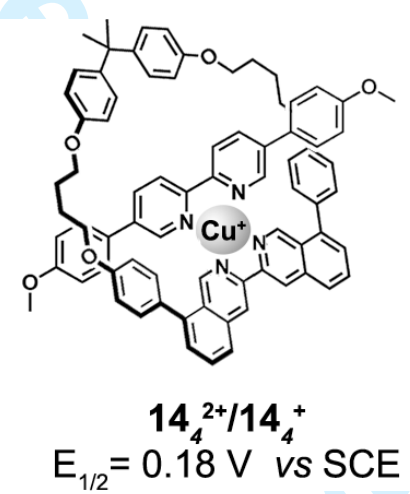

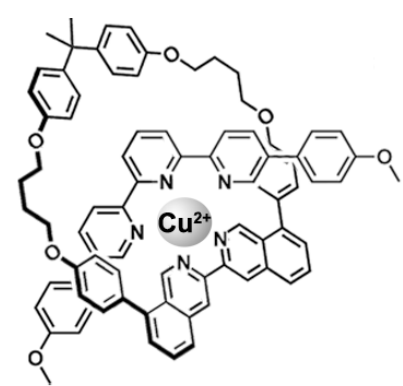

$15_{5}{ }^{2+} / 15_{4}^{+}$ $E_{1 / 2}=-0.03 \vee$ vs SCE

Scheme 9. Reference complexes for electrochemical investigations.

From the redox potentials of the $[\mathrm{Cu}(\mathrm{dpbiiq})(\mathrm{dpp})]^{+}$and $[\mathrm{Cu}(\mathrm{dpbiiq})(\mathrm{bipy})]^{2+}$ complexes, one estimates a driving force of only $0.16 \mathrm{eV}$ for the phenanthroline-to-bipyridine gliding motion. Thus, the driving forces for the shuttling process differ significantly between rotaxane $\mathbf{1 0}$ and rotaxane $\mathbf{1 2}$. The relatively low oxidation potential of the $[\mathrm{Cu} \text { (dpbiiq)(bipy) }]^{+}$complex $(0.18 \mathrm{~V}$ vs. SCE) is indicative of a stabilization of the $\mathrm{Cu}$ (II) oxidation state that is likely to be caused by a rearrangement of the coordination sphere to square planar or even octahedral geometry.

With this basic knowledge at hand, we undertook an electrochemical study of the new phenanthrolinebipyridine shuttle, ${ }^{[56]}$ similar to that discussed above for the phenanthroline-terpyridine system, using different potential scan rates to obtain kinetic information on the shuttling motion. Representative cyclic voltammetry data resulting from this work are shown in Figure 3. 

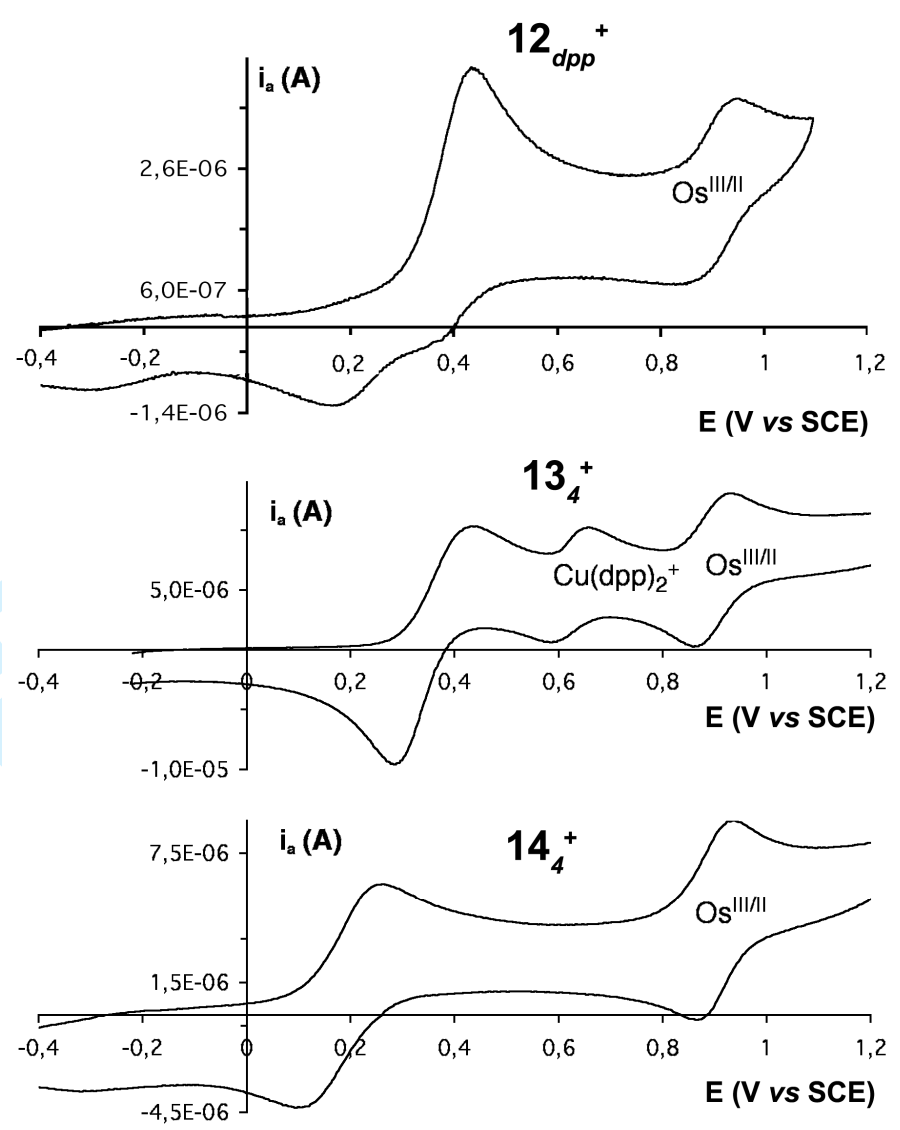

Figure 3. Cyclic voltammograms of shuttle $\mathbf{1 2}$ and the reference complexes $\mathbf{1 3}$ and $\mathbf{1 4}$ recorded on a $\mathrm{Pt}$ working electrode in $\mathrm{CH}_{2} \mathrm{Cl}_{2} / \mathrm{CH}_{3} \mathrm{CN}$ (1:9) with $0.1 \mathrm{M} \mathrm{Bu}_{4} \mathrm{NPF}_{6}$ at $100 \mathrm{mV} / \mathrm{s}$. The reversible redox couple at $0.9 \mathrm{~V}$ vs SCE is due Os(tterpy) ${ }_{2}{ }^{2+}$ (tterpy $=4^{\prime}$ - $p$-tolyl-2,2',6',2"-terpyridine) which was used as an internal reference in this work.

Through comparison of the three data sets in Figure 3, the assignment of the different redox waves observed for shuttle 12 becomes straightforward: The oxidative wave of shuttle 12 around $0.42 \mathrm{~V}$ vs. SCE is also observed in the voltammogram of $[\mathrm{Cu}(\mathrm{dpbiiq})(\mathrm{dpp})]^{+}$reference complex $\mathbf{1 3}$ and therefore can be assigned to $\mathrm{Cu}(\mathrm{I})$ oxidation with the macrocyle located at the 1,10-phenanthroline station. In the voltammogram of complex 13, there is an additional oxidation wave around $0.65 \mathrm{~V}$ vs. SCE that we attribute to a $\left[\mathrm{Cu}(\mathrm{dpp})_{2}\right]^{+}$ impurity that is formed under the experimental conditions used for the synthesis of $\mathbf{1 3}$. This seems to be inevitable due to the high thermodynamic stability of the $\left[\mathrm{Cu}(\mathrm{dpp})_{2}\right]^{+}$complex. The reductive sweep of shuttle 12 exhibits a wave around $0.18 \mathrm{~V}$ which coincides with the reduction wave observed in the voltammogram of $[\mathrm{Cu} \text { (dpbiiq)(bipy) }]^{2+/+}$ reference complex 14 rather than with the reduction wave observed for $[\mathrm{Cu}(\mathrm{dpbiiq})(\mathrm{dpp})]^{2+/+}$ reference complex 13. This is a clear indication that at the potential scan rate used for the experiments in Figure $3(100 \mathrm{mV} / \mathrm{s})$, by the time the oxidative sweep is finished and the reductive sweep begins, the copper-macrocycle entity has already travelled from its initial position at the phenanthroline station to the bipyridine station. By analogy to our prior investigations, we varied the potential scan rates to obtain information on the shuttling kinetics. Figure 4 shows a series of 
voltammograms obtained during this work.
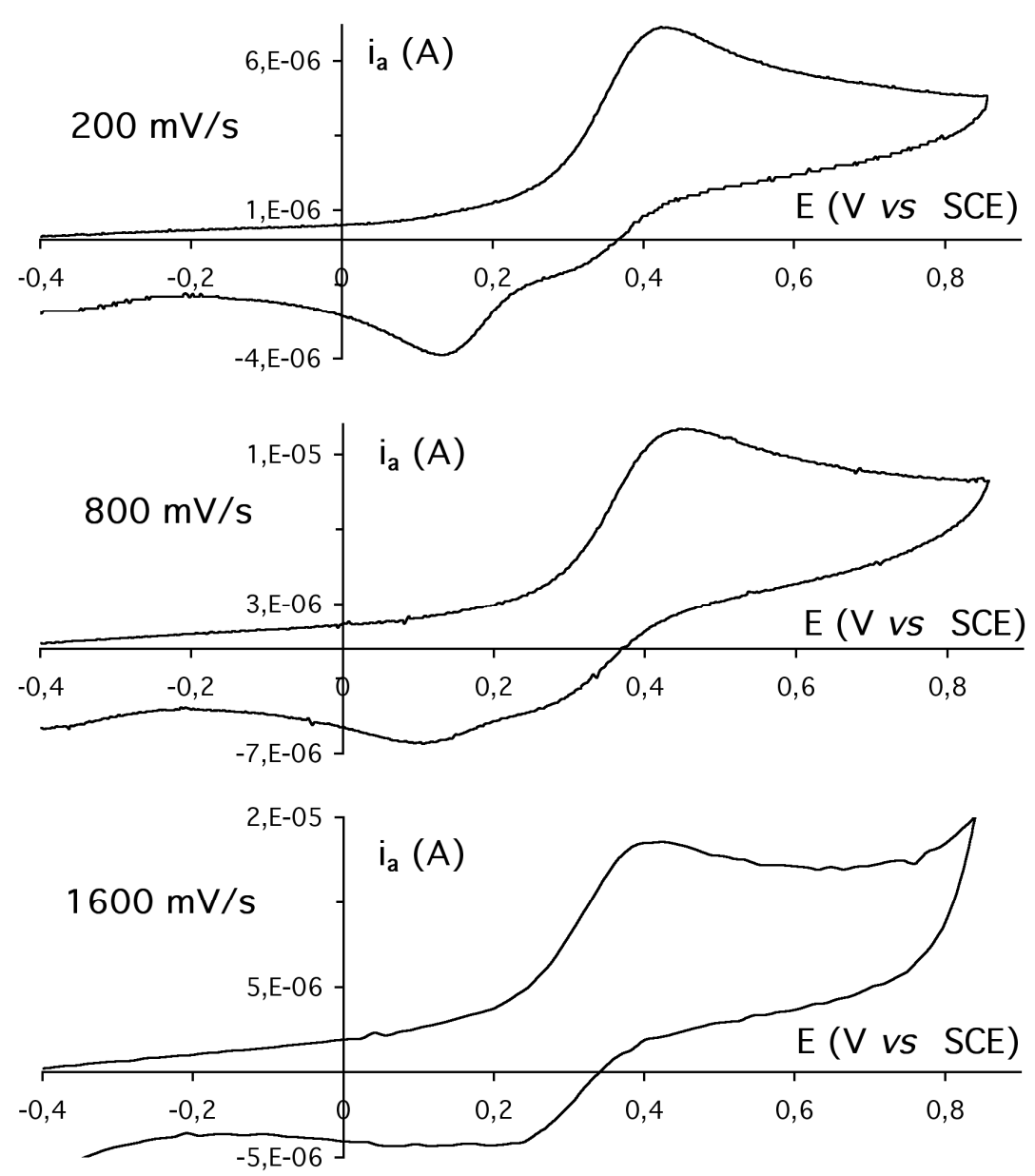

Figure 4. Cyclic voltammograms of rotaxane 12 recorded at various potential scan rates in $\mathrm{CH}_{2} \mathrm{Cl}_{2} / \mathrm{CH}_{3} \mathrm{CN}$ (1:9) with $0.1 \mathrm{M} \mathrm{Bu}_{4} \mathrm{NPF}_{6}$.

As the scan rate is increased from $200 \mathrm{mV} / \mathrm{s}$ to $800 \mathrm{mV} / \mathrm{s}$ and finally $1600 \mathrm{mV} / \mathrm{s}$, there are no significant alterations in the oxidative sweep, but the reductive scan gradually changes. At $200 \mathrm{mV} / \mathrm{s}$ one still observes the reduction wave associated with the $\left[\mathrm{Cu}(\text { dpbiiq)(bipy) }]^{2+/+}\right.$ complex, i. e., reduction of $\mathrm{Cu}(\mathrm{II})$ at the bipyridine station. At $1600 \mathrm{mV} / \mathrm{s}$ on the other hand, the reduction occurs at a significantly higher potential and coincides with the reduction wave observed for the $[\mathrm{Cu}(\mathrm{dpbiiq})(\mathrm{dpp})]^{2+/+}$ complex $\mathbf{1 3}$ from Figure 3. This shows that at this scan rate, $\mathrm{Cu}(\mathrm{II})$ is reduced while located at the phenanthroline station. Under these experimental conditions, the traveling motion from the phenanthroline to the bipyridine station cannot keep up with the high potential scan rate: Reduction of $\mathrm{Cu}(\mathrm{II})$ occurs while the metal is still in its initial coordination environment. Remarkable is the complete absence of an oxidative wave in the voltammogram of shuttle 12 that could be attributed to $\mathrm{Cu}(\mathrm{I})$ oxidation in a biisoquinoline-bipyridine coordination, even at the highest scan rate of $1600 \mathrm{mV} / \mathrm{s}$. This indicates that molecular movement originating from the unstable $[\mathrm{Cu} \text { (dpbiiq)(bipy) }]^{+}$complex is much faster than the shuttling motion originating from thermodynamically unstable $[\mathrm{Cu}(\mathrm{dpbiiq})(\mathrm{dpp})]^{2+}$ complex. From our scan-rate dependent cyclic voltammetry experiments, a rate 
constant of $0.8 \mathrm{~s}^{-1}$ can be extracted for the shuttling motion of macrocycle $\mathbf{8}$ from the dpp station to the bipy ligand, whereas for the reverse motion a lower limit of $50 \mathrm{~s}^{-1}$ is estimated. The magnitude of these rate constants is comparable to that for the dpp-terpy shuttle from Scheme 6, indicating that the lower thermodynamic driving force in the dpp-bipy shuttle from Scheme 8 is not a crucial factor as far as the shuttling kinetics are concerned.

With the dpp-terpy and dpp-bipy two-station shuttles completely characterized and identified as fully operational systems, the construction of a three-station shuttle comprised of one dpp, one bipy and a terpy station became a realistic goal. We have therefore prepared rotaxane 16 as shown in Scheme 10. ${ }^{\text {[29] }}$

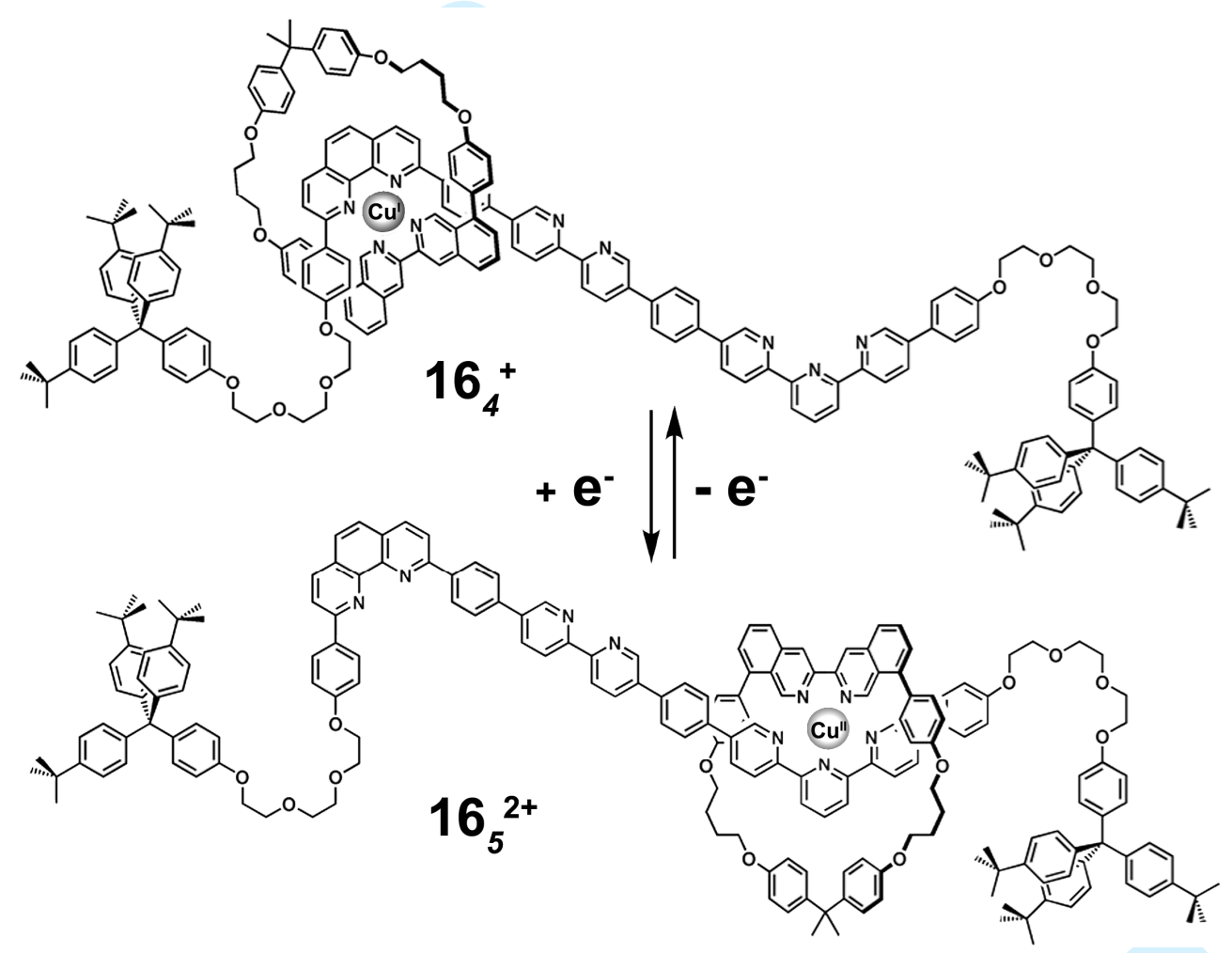

Scheme 10. Three-station rotaxane 16 containing dpp, bipy and terpy stations on the molecular axis and dpbiiq-based macrocycle $\mathbf{8}$. The subscripts indicate the coordination numbers of the copper center.

The estimated distance between the two terminal coordination sites on the three-station molecular axis is 23 $\AA$, which is considerably larger than in all previously investigated molecular shuttles of this type. Depicted in Scheme 10 are the thermodynamically stable forms for $\mathrm{Cu}(\mathrm{I})$ and $\mathrm{Cu}(\mathrm{II})$. From the studies of the twostation shuttles described above, the following order of thermodynamic stabilities for the individual copper complexes is expected: $\left[\mathrm{Cu}(\text { dpbiiq)(terpy) }]^{+}<\left[\mathrm{Cu}(\text { dpbiiq)(bipy) }]^{+}<\left[\mathrm{Cu}(\text { dpbiiq)(dpp) }]^{+}\right.\right.\right.$for the copper(I) species and a reversed order yielding $[\mathrm{Cu}(\mathrm{dpbiiq})(\mathrm{dpp})]^{2+}<[\mathrm{Cu} \text { (dpbiiq)(bipy) }]^{2+}<[\mathrm{Cu} \text { (dpbiiq)(terpy) }]^{2+}$ for the copper(II) species. Thus, the bipyridine ligand merely serves as an intermediate station to bridge the long distance between the two thermodynamically favored positions. It was hoped that this, along with the fact 
that a sterically non-hindering dpbiiq-based macrocycle was threaded onto the molecular axis, would enable the molecular ring to move from one end to the other at reasonable rates. The expected shuttling sequence is illustrated in Scheme 11. Upon oxidation of $\mathrm{Cu}(\mathrm{I})$ to $\mathrm{Cu}(\mathrm{II})$, metal center and ring are expected to travel from the inital dpp-position to the bipy station and from there onwards to the thermodynamically favored terpy ligand (right half of Scheme 11). Upon reduction of the $\left[\mathrm{Cu}(\text { dpbiiq)(terpy) }]^{2+}\right.$ complex, the metalmacrocycle entity is anticipated to travel the reverse direction, again by way of the bipy station as a coordination site of intermediate stability (left half of Scheme 11).

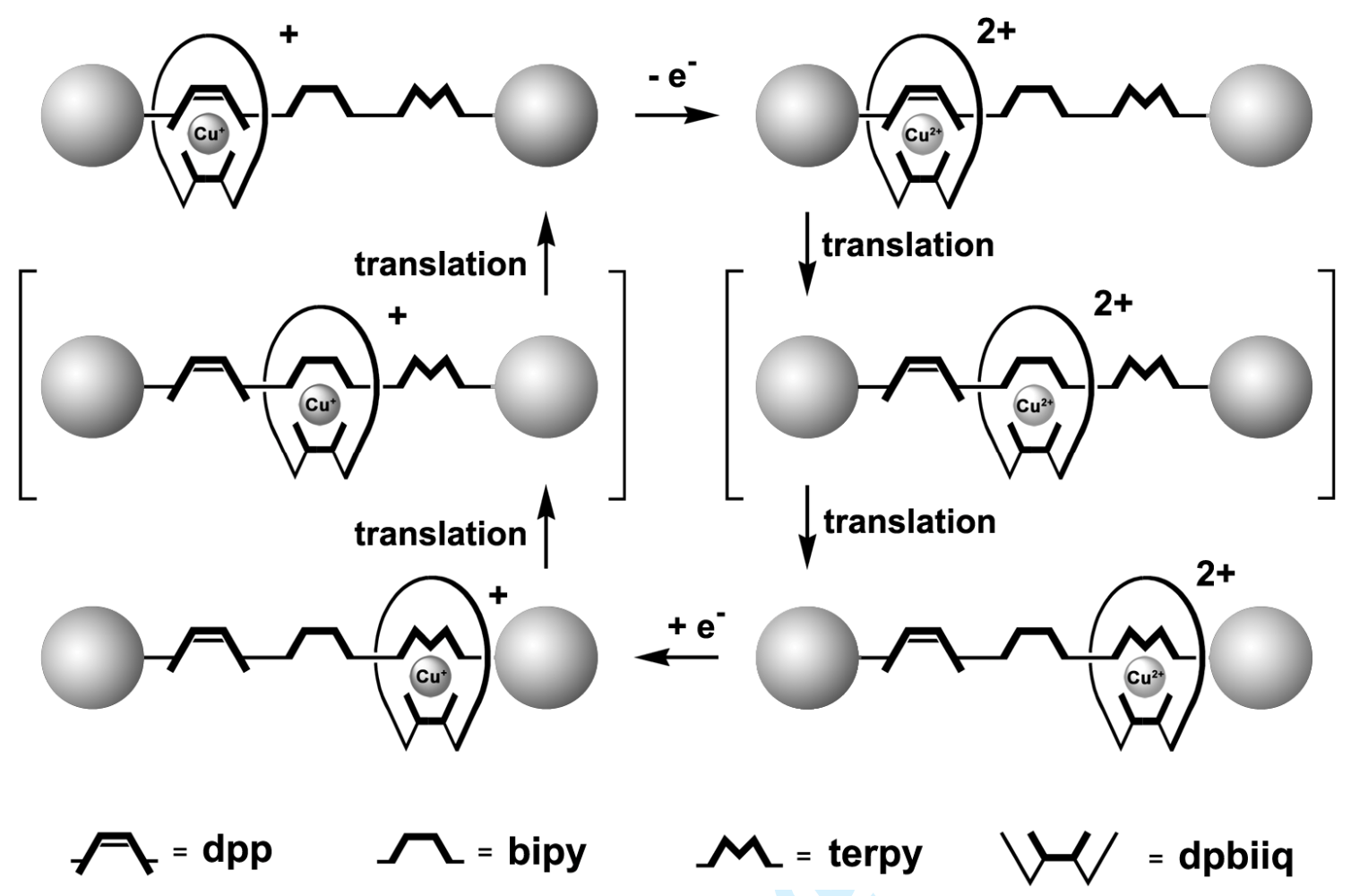

Scheme 11. Operating principle of the molecular three-station shuttle 16 from Scheme 10.

Cyclic voltammetry was performed to investigate the shuttling processes in this long-distance shuttle. Figure 5 shows a comparison of the voltammograms obtained for three-station shuttle $\mathbf{1 6},[\mathrm{Cu}(\mathrm{dpbiiq})(\mathrm{dpp})]^{+}$ reference complex 13, $\left[\mathrm{Cu}(\text { dpbiiq)(bipy) }]^{+}\right.$reference complex $14,\left[\mathrm{Cu}(\text { dpbiiq)(terpy) }]^{2+}\right.$ reference complex $\mathbf{1 5}$, and two-station dpp-terpy shuttle $\mathbf{1 0 .}$

Figure 5. Comparison of the cyclic voltammograms for three-station shuttle 16, $[\mathrm{Cu}(\mathrm{dpbiiq})(\mathrm{dpp})]^{+}$ reference complex 13, $\left[\mathrm{Cu}(\text { dpbiiq)(bipy) }]^{+}\right.$reference complex $14,[\mathrm{Cu} \text { (dpbiiq)(terpy) }]^{2+}$ reference complex 15, and two-station dpp-terpy shuttle 10. The measurements were performed in $\mathrm{CH}_{2} \mathrm{Cl}_{2} / \mathrm{CH}_{3} \mathrm{CN}$ (1:9) with $0.1 \mathrm{M} \mathrm{Bu}_{4} \mathrm{NPF}_{6}$ using a Pt working electrode and a scan rate of $100 \mathrm{mV} / \mathrm{s}$. The reversible wave at $0.9 \mathrm{~V}$ vs. $\mathrm{SCE}$ is due to Os(tterpy) ${ }_{2}{ }^{2+}$ (tterpy $=4^{\prime}$ - $p$-tolyl-2,2, $, 6^{\prime}, 2^{\prime \prime}$-terpyridine) which was used as an internal reference. 
From this comparison, assignment of the redox waves observed for the three-station shuttle $\mathbf{1 6}$ is straightforward: The oxidative wave observed for $\mathbf{1 6}$ at $0.38 \mathrm{~V}$ vs. SCE coincides with the wave at $0.37 \mathrm{~V}$ vs. SCE for two-station shuttle $\mathbf{1 0}$ and previously assigned to $\mathrm{Cu}(\mathrm{I})$ oxidation in four-coordinate dpbiiq-dpp environment. This assignment is in line with the oxidation potential of $0.38 \mathrm{~V}$ vs. SCE determined for $[\mathrm{Cu}(\mathrm{dpbiiq})(\mathrm{dpp})]^{+}$reference complex 13. In the reductive sweep of the voltammogram of three-station shuttle 16, there is only one clear reduction wave, and it is located at $-0.02 \mathrm{~V}$ vs. SCE. This coincides with the reduction wave observed for $\left[\mathrm{Cu}(\mathrm{dpbiiq})(\text { terpy) }]^{2+}\right.$ reference complex $\mathbf{1 5}$, and consequently can be assigned to reduction of $\mathrm{Cu}(\mathrm{II})$ in five-coordinate dpbiiq-terpy environment. The overall appearance of the voltammogram of three-station shuttle $\mathbf{1 6}$ is thus very similar to that of two-station dpp-terpy shuttle 10: The same oxidation and reduction waves are observed, and there are no additional waves in the voltammogram of $\mathbf{1 6}$ that would be indicative of bipyridine-ligated copper. In other words, there is no electrochemical evidence for copper being coordinated to the intermediate bipy station. This observation suggests that translation away from the bipy ligand is fast in both directions: For $\mathrm{Cu}(\mathrm{II})$, bipy-to-terpy translation must be faster than dpp-to-bipy translation, and for $\mathrm{Cu}(\mathrm{I})$, bipy-to-dpp translation must be faster than terpy-to-bipy translation. Under these circumstances, the stationary concentration of the intermediate bipy-complex always stays low and its electrochemical signal cannot be detected. Indeed, from our experiments on the three-station shuttle it is not clear whether the bipy ligand behaves as a real station that ligates to copper for a certain residence time.

Anyhow, scan-rate dependent cyclic voltammetry experiments similar to those presented in Figures 2 and 4 allow us to estimate a rate constant of $0.4 \mathrm{~s}^{-1}$ for the shuttling motion from the dpp site to the terpy ligand upon $\mathrm{Cu}(\mathrm{I})$ oxidation, and the reverse process following $\mathrm{Cu}(\mathrm{II})$ reduction occurs with $\mathrm{k} \geq 50 \mathrm{~s}^{-1}$.

\section{Conclusions}

The use of a sterically non-hindering biisoquinoline chelate allows the construction of molecular shuttles that exhibit greatly improved shuttling kinetics when compared to analogous systems that are based on sterically demanding macrocycles. When threaded on exactly the same molecular axis, a biisoquinolinebased 39-membered macrocycle moves several orders of magnitude more rapidly than a 30-membered phenanthroline-based macrocycle. When threaded onto a rigid molecular axis in which the overall distance between the two terminal stations is increased from roughly $11 \AA$ to about $23 \AA$, the shuttling kinetics for the biisoquinoline-based macrocycle do not decrease significantly. While it is likely that the presence of a third station of intermediate thermodynamic stability facilitates shuttling over the $23 \AA$ distance, there is no doubt that the key to these results is the biisoquinoline core of the mobile ring. With respect to the previously investigated phenanthroline-based systems it may thus be stated that the new biisoquinoline-macrocycles are 
not only bigger, they also lead to faster shuttling kinetics in rotaxane-type molecular machines. Thus, bigger rings give rise to better performance due to faster molecular movements, and sterically non-hindering biisoquinoline chelates are truly bigger, better and faster.

\section{Acknowledgments}

We thank all the skilful and motivated researchers who contributed to this work, namely David Hanss, Alexander I. Prikhod'ko, and Pirmin Roesel. Financial support from the Région Alsace (F. D. and J. L.), the European Commission, and the Swiss National Science Foundation (O. S. W.) is acknowledged. We thank Kari Rissanen and his group for X-ray crystallographic work.

\section{References}

[1] D. B. Amabilino, J. F. Stoddart, Chem. Rev. 1995, 95, 2725.

[2] C. P. Collier, E. W. Wong, M. Belohradsky, F. M. Raymo, J. F. Stoddart, P. J. Kuekes, R. S. Williams, J. R. Heath, Science 1999, 285, 391.

[3] A. Harada, Acc. Chem. Res. 2001, 34, 456.

[4] K. Kinbara, T. Aida, Chem. Rev. 2005, 105, 1377.

[5] A. Kocer, M. Walko, W. Meijberg, B. L. Feringa, Science 2005, 309, 755.

[6] B. Champin, P. Mobian, J.-P. Sauvage, Chem. Soc. Rev. 2007, 36, 358.

[7] E. R. Kay, D. A. Leigh, F. Zerbetto, Angew. Chem. Int. Ed. 2007, 46, 72.

[8] J. E. Green, J. W. Choi, A. Boukai, Y. Bunimovich, E. Johnston-Halperin, E. Delonno, Y. Luo, B. A. Sheriff, K. Xu, Y. S. Shin, H.-R. Tseng, J. F. Stoddart, J. R. Heath, Nature 2007, 445, 414.

[9] V. Balzani, M. Venturi, A. Credi, Molecular Devices and Machines-Concepts and perspectives for the Nanoworld, Wiley VCH, Weinheim, 2008.

A. Livoreil, C. O. Dietrich-Buchecker, J.-P. Sauvage, J. Am. Chem. Soc. 1994, 116, 9399.

D. J. Cárdenas, A. Livoreil, J.-P. Sauvage, J. Am. Chem. Soc. 1996, $118,11980$.

N. Solladie, J.-C. Chambron, C. O. Dietrich-Buchecker, J.-P. Sauvage, Angew. Chem. Int. Ed. 1996, $35,906$. J.-P. Collin, P. Gaviña, J.-P. Sauvage, New J. Chem. 1997, 21, 525.

[15] J. Frey, T. Kraus, V. Heitz, J.-P. Sauvage, Chem. Eur. J. 2007, 13, 7584.

[16] G. Schill, Catenanes, Rotaxanes and Knots, Academic Press, New York and London, 1971.

[17] C. O. Dietrich-Buchecker, J.-P. Sauvage, Chem. Rev. 1987, 87, 795.

[18] D. B. Amabilino, J. F. Stoddart, Chem. Rev. 1995, 95, 2725.

[19] J.-P. Sauvage, Acc. Chem. Res. 1998, 31, 611.

[20] J.-P. Sauvage, C. O. Dietrich-Buchecker, Molecular Catenanes, Rotaxanes and Knots, Wiley-VCH, Weinheim, 1999.

[21] C. O. Dietrich-Buchecker, J.-P. Sauvage, J.-P. Kintzinger, Tetrahedron Lett. 1983, 24, 5095.

[22] C. O. Dietrich-Buchecker, J.-P. Sauvage, J.-M. Kern, J. Am. Chem. Soc. 1984, 106, 3043.

[23] F. Durola, J.-P. Sauvage, O. S. Wenger, Chem. Commun. 2006, 171.

[24] F. Durola, D. Hanss, P. Roesel, J.-P. Sauvage, O. S. Wenger, Eur. J. Org. Chem. 2007, 125.

[25] F. Durola, O. S. Wenger, J.-P. Sauvage, Helv. Chim. Acta 2007, 90, 1439.

[26] F. Durola, L. Russo, J.-P. Sauvage, K. Rissanen, O. S. Wenger, Chem. Eur. J. 2007, 13, 8749.

[27] B. Ventura, F. Barigelletti, F. Durola, L. Flamigni, J.-P. Sauvage, O. S. Wenger, Dalton Trans. $2008,491$.

[28] F. Durola, J.-P. Sauvage, O. S. Wenger, Coord. Chem. Rev. 2010, 254, 1748.

[29] R. A. Bissell, E. Córdova, A. E. Kaifer, J. F. Stoddart, Nature 1994, 369, 133.

[30] H. Murakami, A. Kawabuchi, K. Kotoo, M. Kunitake, N. Nakashima, J. Am. Chem. Soc. 1997, 119, 7605.

[31] G. W. H. Wurpel, A. M. Brouwer, I. H. M. van Stokkum, A. Farran, D. A. Leigh, J. Am. Chem. Soc. $2001,123,11327$.

[32] C. A. Stanier, S. J. Alderman, T. D. W. Claridge, H. L. Anderson, Angew. Chem. Int. Ed. 2002, 41, 1769. 
[33] S.-Y. Chang, K.-S. Jeong, J. Org. Chem. 2003, 68, 4014.

[34] C. M. Keaveney, D. A Leigh, Angew. Chem. Int. Ed. 2004, 43, 1222.

[35] E. M. Pérez, D. T. F. Dryden, D. A. Leigh, G. Teobaldi, F. Zerbetto, J. Am. Chem. Soc. 2004, 126, 12210.

[36] Q.-C. Wang, D.-H. Qu, J. Ren, K. Chen, H. Tian, Angew. Chem. Int. Ed. 2004, 43, 2661.

[37] B. Korybut-Daszkiewicz, A. Wieckowska, R. Bilewicz, S. Domagała, K. Wozniak, Angew. Chem. Int. Ed. $2004,43,1668$.

[38] V. Balzani, M. Clemente-León, A. Credi, B. Ferrer, M. Venturi, A. H. Flood, J. F. Stoddart, PNAS 2006, $103,1178$.

[39] V. Sindelar, S. Silvi, A. E. Kaifer, Chem. Commun. 2006, 2185.

[40] K. Hirose, Y. Shiba, K. Ishibashi, Y. Doi, Y. Tobe, Chem. Eur. J. 2008, 14, 3427.

[41] T. Umehara, H. Kawai, K. Fujiwara, T. Suzuki, J. Am. Chem. Soc. 2008, 130, 13981.

[42] G. Fioravanti, N. Haraszkiewicz, E. R. Kay, S. M. Mendoza, C. Bruno, M. Marcaccio, P. G. Wiering, F. Paolucci, P. Rudolf, A. M. Brouwer, D. A. Leigh, J. Am. Chem. Soc. 2008, 130, 2593.

[43] F. Coutrot, E. Busseron, Chem. Eur. J. 2009, 15, 5186.

[44] F. Durola, J.-P. Sauvage, Angew. Chem. Int. Ed. 2007, 46, 3537.

[45] F. Durola, J. Lux, J.-P. Sauvage, Chem. Eur. J. 2009, 15, 4124.

[46] J.-P. Collin, F. Durola, J. Lux, J.-P. Sauvage, Angew. Chem. Int. Ed. 2009, 48, 8532.

[47] J.-P. Collin, F. Durola, P. Mobian, J.-P. Sauvage, Eur. J. Inorg. Chem. 2007, 2420.

[48] R. S. Nicholson, I. Shain, Anal. Chem. 1964, 36, 706.

[49] L. Raehm, J.-M. Kern, J.-P. Sauvage, Chem. Eur. J. 1999, 5, 3310.

[50] J.-P. Collin, P. Gaviña, J.-P. Sauvage, Chem. Commun. 1996, 17, 2005.

[51] J.-M. Kern, L. Raehm, J.-P. Sauvage, B. Divisia-Blohorn, P.-L. Vidal, Inorg. Chem. 2000, $39,1555$.

[52] I. Poleschak, J.-M. Kern, J.-P. Sauvage, Chem. Commun. 2004, 474.

[53] U. Létinois-Halbes, D. Hanss, J. M. Beierle, J.-P. Collin, J.-P. Sauvage, Org. Lett. 2005, 7, 5753.

[54] A. S. Lane, D. A. Leigh, A. Murphy, J. Am. Chem. Soc. 1997, 119, 11092.

[55] H.-R. Tseng, S. A. Vignon, J. F. Stoddart, Angew. Chem. Int. Ed. 2003, 42, 1491.

[56] J.-P. Collin, F. Durola, J. Lux, J.-P. Sauvage, New. J. Chem. 2010, 34, 34. 


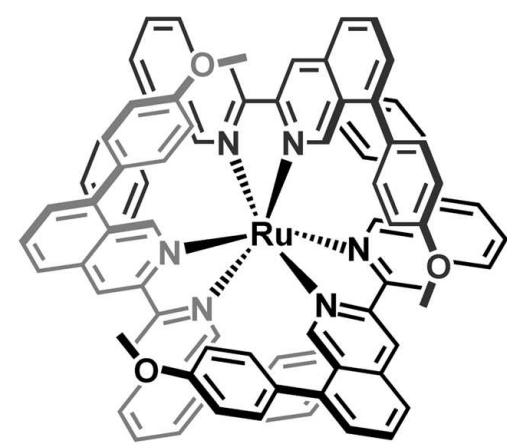

$5^{2+}$
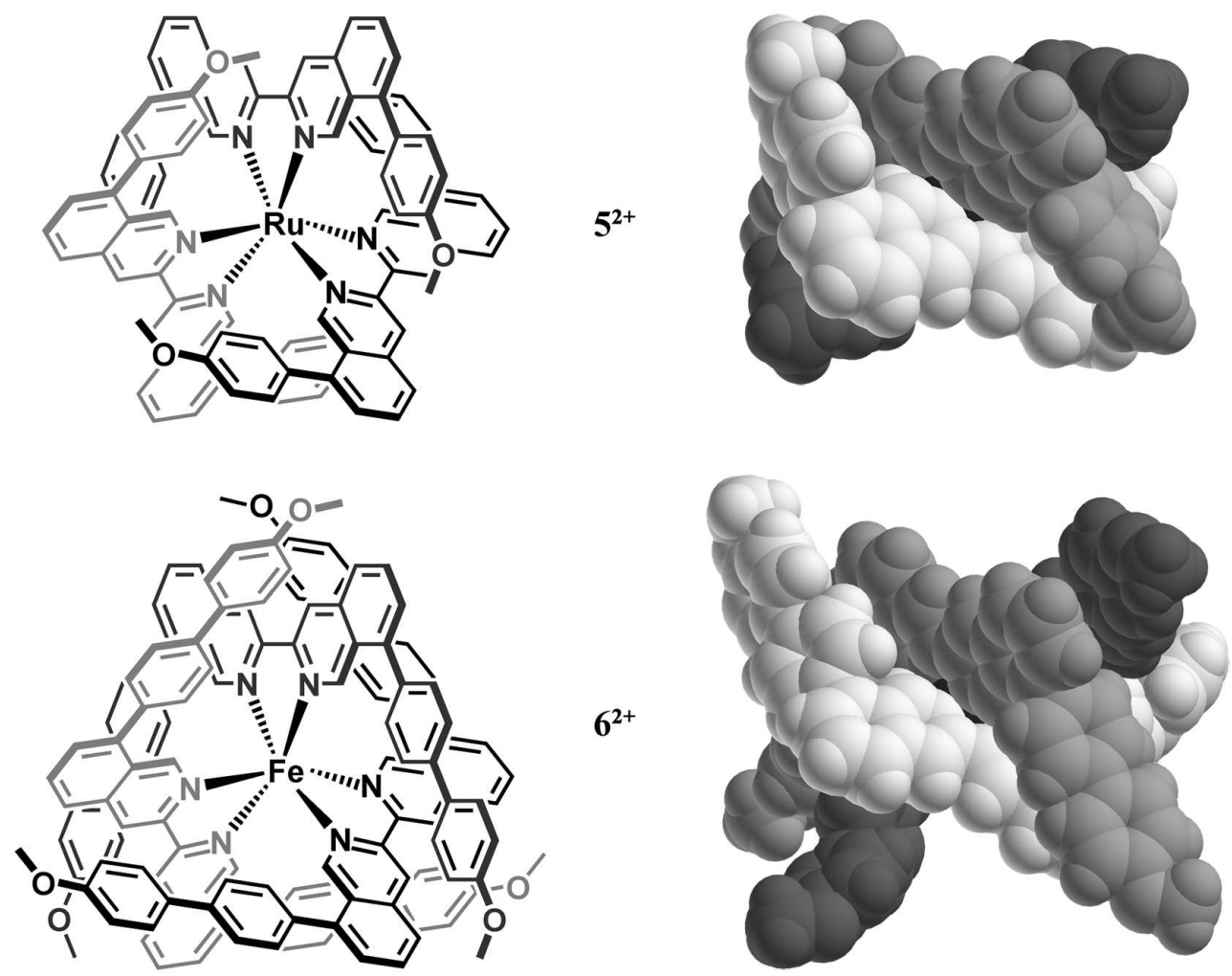

Left: Chemical structures of [Ru(8,8'-dianisyl-3,3'-biisoquinoline)3]2+ and [Fe(8,8'-diphenylanisylbiisoquinoline)3]2+. Right: X-ray crystal structures of these complexes. [26] $95 \times 75 \mathrm{~mm}(450 \times 450 \mathrm{DPI})$ 
(a)

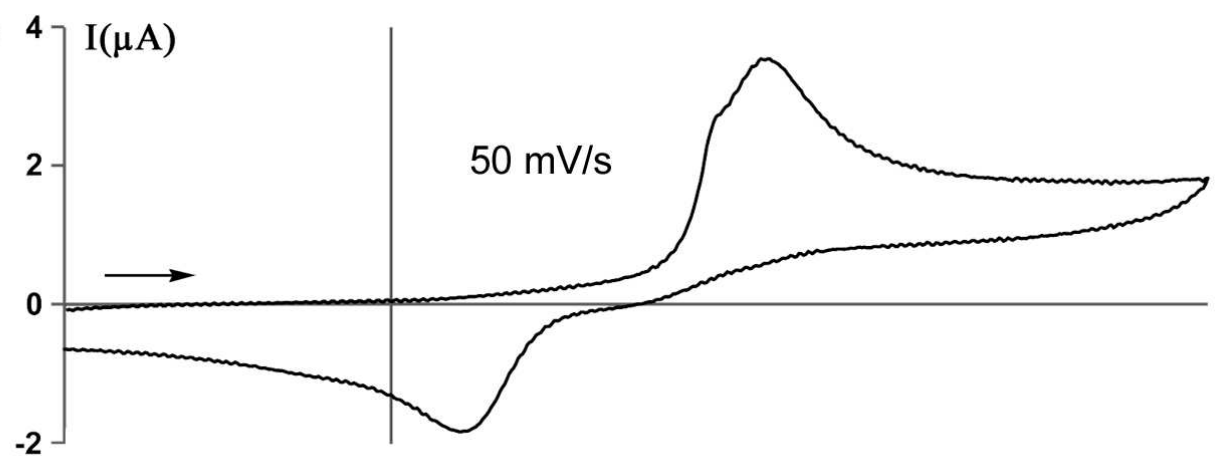

(b)

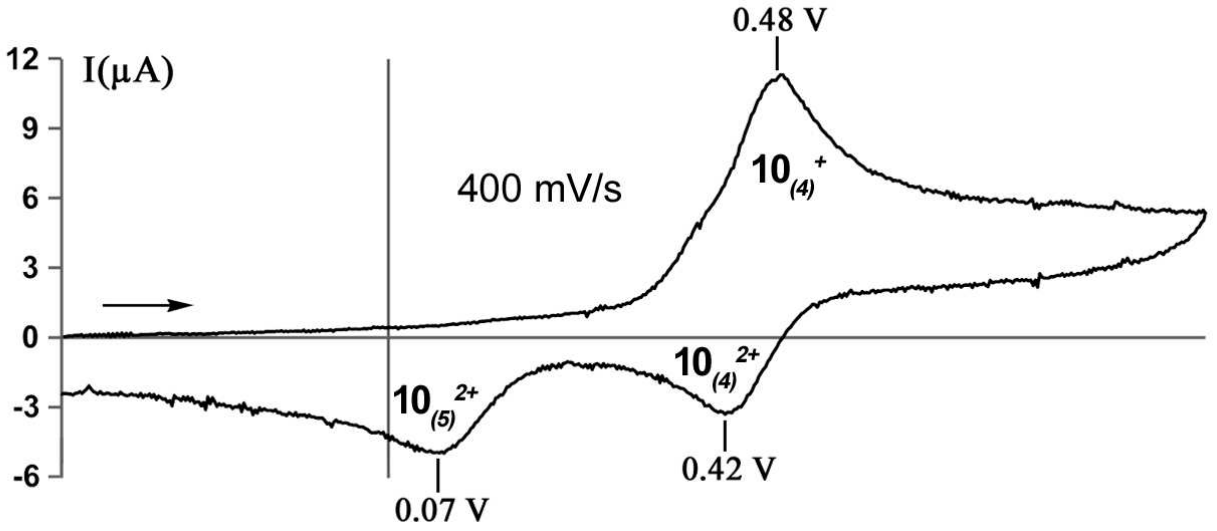

(c)

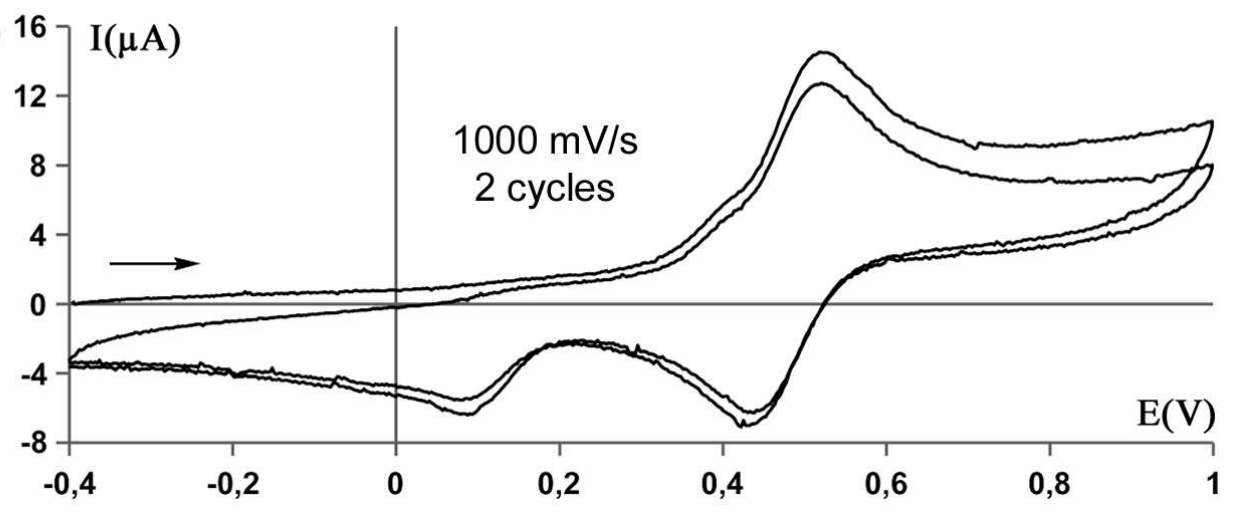

Cyclic voltammograms obtained on the molecular shuttle from Scheme 6 at three different potential scan rates. See reference [45] for experimental details. Potentials are reported versus SCE. $94 \times 109 \mathrm{~mm}(350 \times 350 \mathrm{DPI})$ 

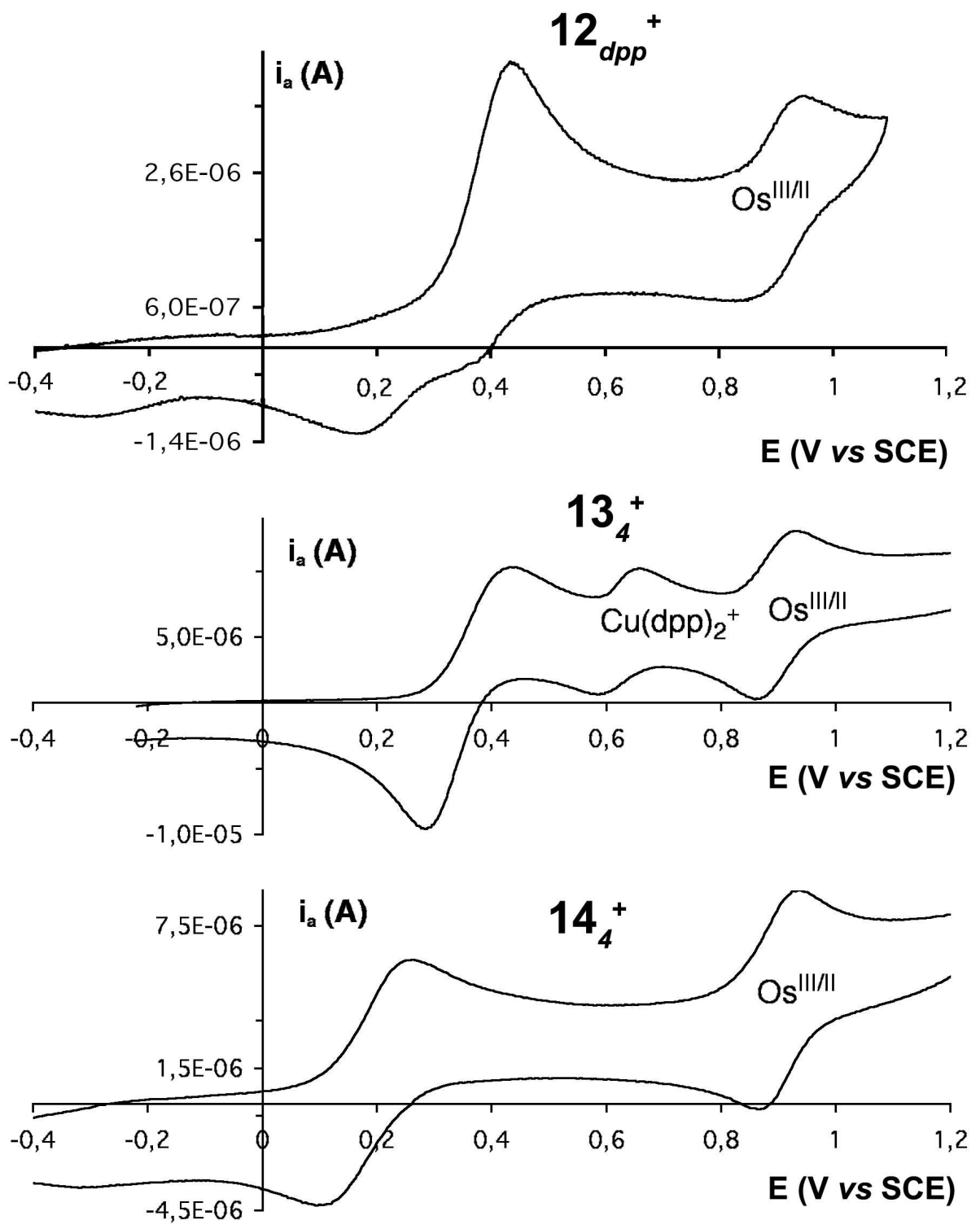

Cyclic voltammograms of shuttle 12 and the reference complexes 13 and 14 recorded on a $\mathrm{Pt}$ working electrode in $\mathrm{CH} 2 \mathrm{Cl} 2 / \mathrm{CH} 3 \mathrm{CN}(1: 9)$ with $0.1 \mathrm{M} \mathrm{Bu} 4 \mathrm{NPF} 6$ at $100 \mathrm{mV} / \mathrm{s}$. The reversible redox couple at $0.9 \mathrm{~V}$ vs SCE is due Os(tterpy) $22+$ (tterpy $=4^{\prime}$-p-tolyl-2, $2^{\prime}, 6^{\prime}, 2^{\prime \prime}$-terpyridine) which was used as an internal reference in this work. $154 \times 199 \mathrm{~mm}(300 \times 300 \mathrm{DPI})$ 

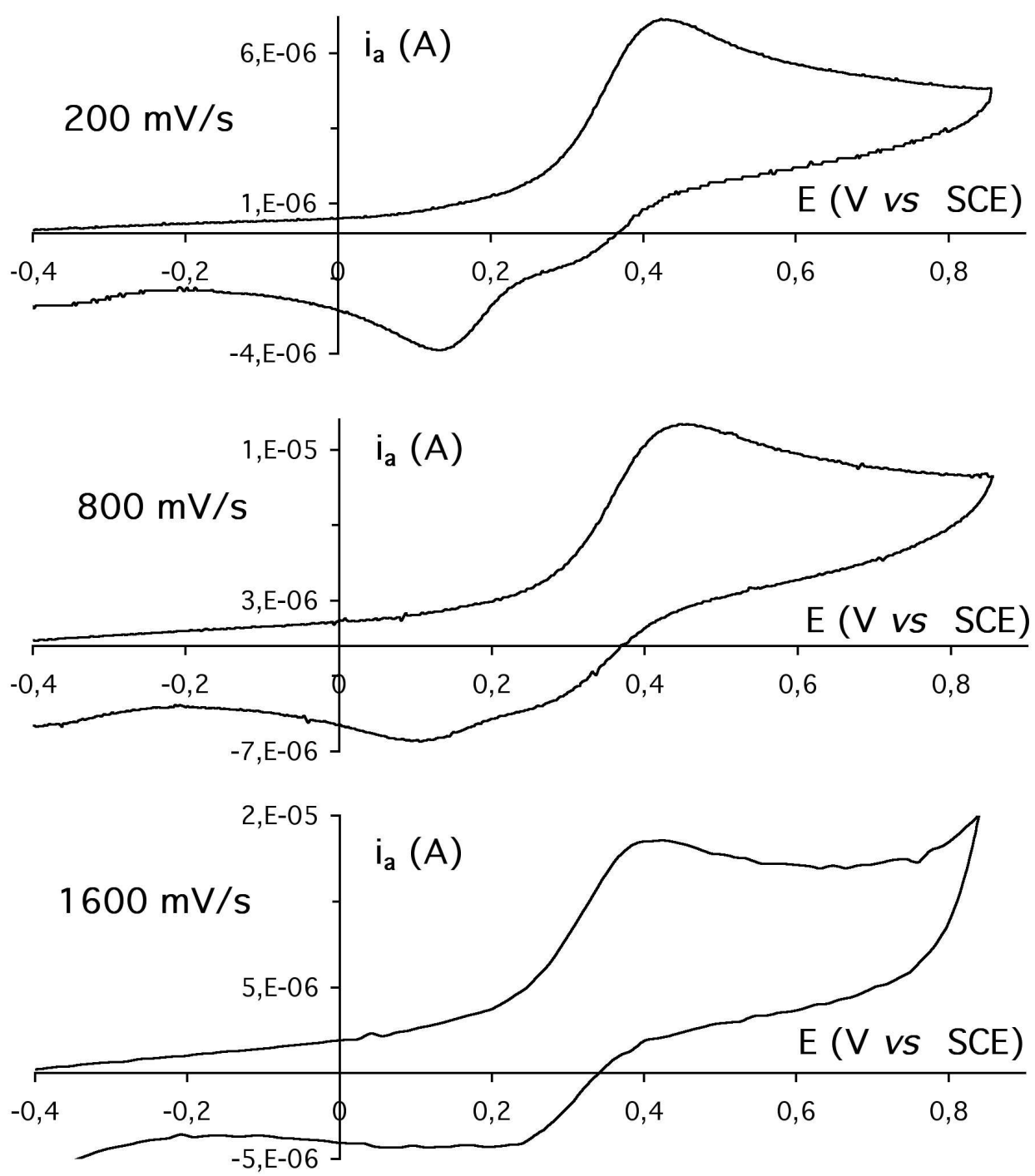

Cyclic voltammograms of rotaxane 12 recorded at various potential scan rates in $\mathrm{CH} 2 \mathrm{Cl} 2 / \mathrm{CH} 3 \mathrm{CN}$ (1:9) with 0.1 M Bu4NPF6.

$159 \times 175 \mathrm{~mm}(300 \times 300 \mathrm{DPI})$ 

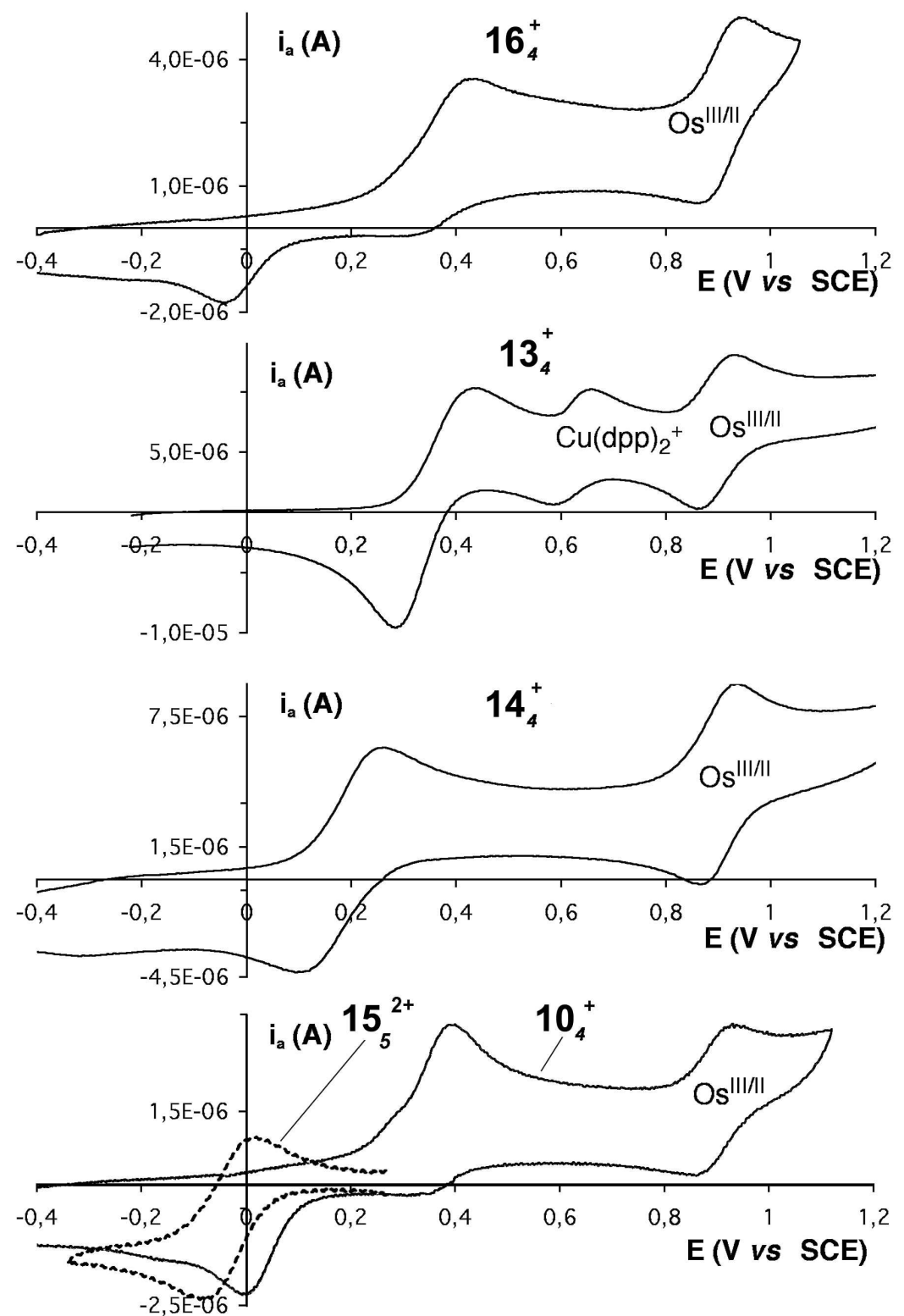

Comparison of the cyclic voltammograms for three-station shuttle $16,[\mathrm{Cu}(\mathrm{dpbiiq})(\mathrm{dpp})]+$ reference complex 13, [Cu(dpbiiq)(bipy)]+ reference complex 14, [Cu(dpbiiq)(terpy)]2+ reference complex 15 , and two-station dpp-terpy shuttle 10 . The measurements were performed in $\mathrm{CH} 2 \mathrm{Cl} 2 / \mathrm{CH} 3 \mathrm{CN}$ (1:9) with $0.1 \mathrm{M}$ Bu4NPF6 using a Pt working electrode and a scan rate of $100 \mathrm{mV} / \mathrm{s}$. The reversible wave at $0.9 \mathrm{~V}$ vs. SCE is due to Os(tterpy) $22+$ (tterpy $=4^{\prime}$-p-tolyl-2, $2^{\prime}, 6^{\prime}, 2^{\prime \prime}$-terpyridine) which was used as an internal reference. $160 \times 227 \mathrm{~mm}(300 \times 300 \mathrm{DPI})$ 


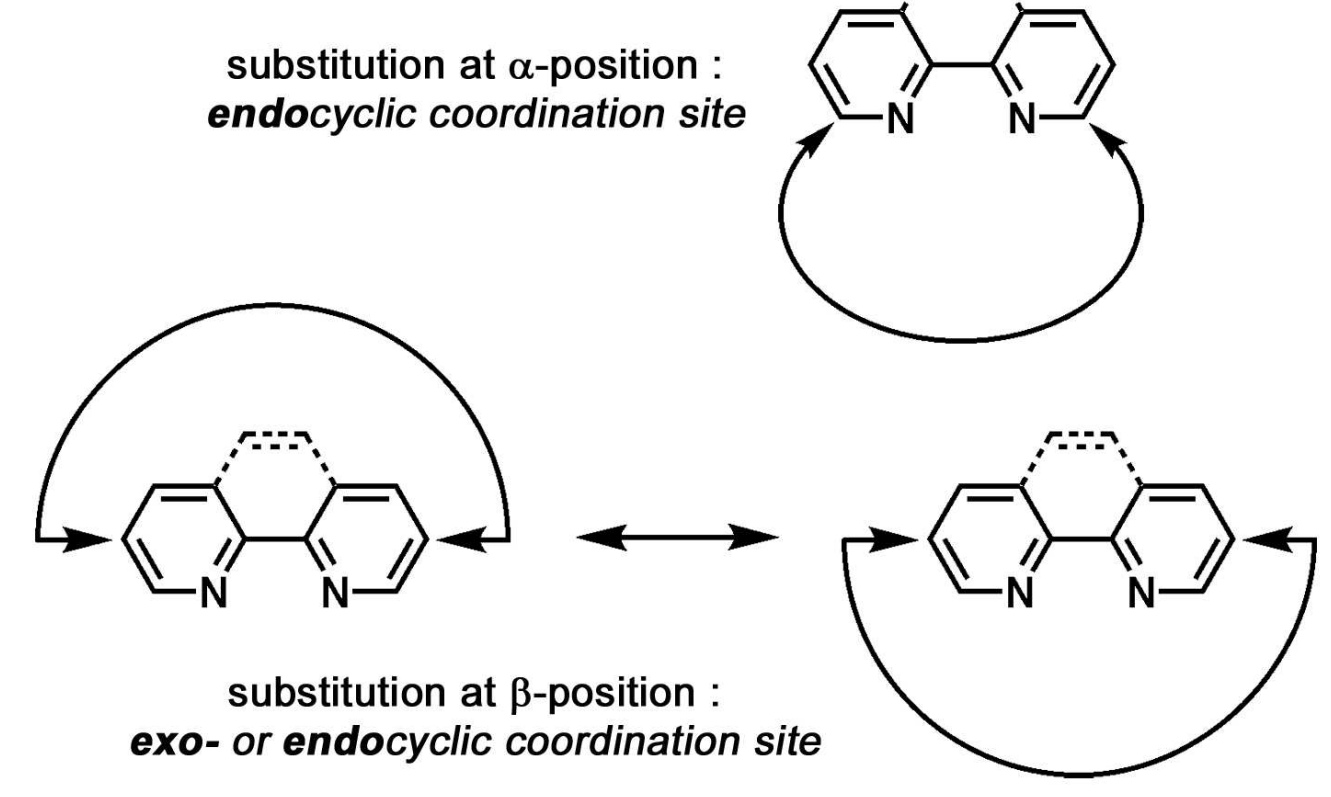

2,9-substitution of 1,10-phenanthroline and 6,6'-substitution of 2,2'-bipyridine results in macrocycles with endocyclic coordination. Substitution at other positions is expected to lead to both endo- and exocyclic macrocycles. $89 \times 57 \mathrm{~mm}(400 \times 400 \mathrm{DPI})$ 


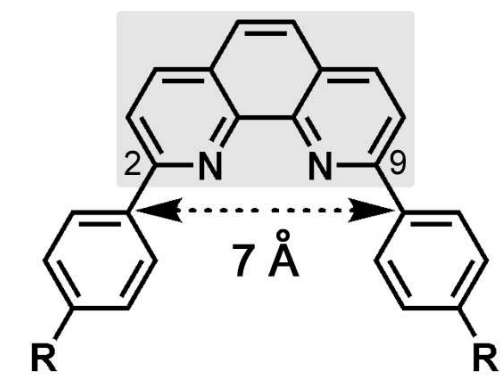

dpp $1: \mathrm{R}=\mathrm{H}$ diphenylphenanthroline

dap 2: $\mathrm{R}=\mathrm{OCH}_{3}$ dianisylphenanthroline

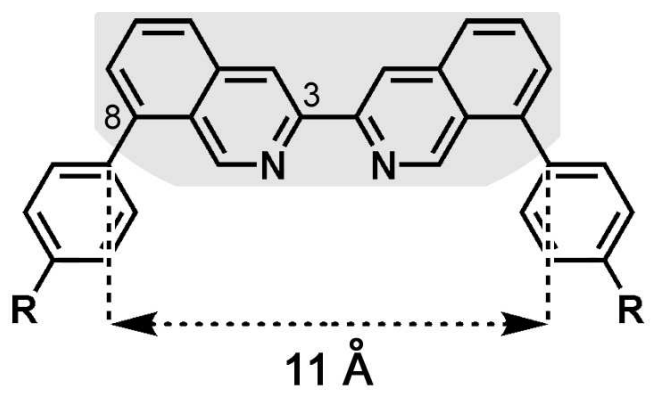

dpbiiq $3: \mathrm{R}=\mathrm{H}$ diphenylbiisoquinoline dabiiq $4: \mathrm{R}=\mathrm{OCH}_{3}$ dianisylbiisoquinoline

Endocyclic ligands based on 2,9-diphenyl-1,10-phenanthroline (ddp) and 8,8'-diphenyl-3,3'biisoquinoline (dpbiiq).

$82 \times 41 \mathrm{~mm}$ ( $450 \times 450$ DPI) 
Working principle of a two-station molecular shuttle comprised of a molecular axis with a bidentate chelate (e. g., a dpp-fragment) and a tridentate ligand (e. g., a terpyridine chelate). The molecular ring is typically a macrocycle incorporating a dpp-fragment. $139 \times 52 \mathrm{~mm}(450 \times 450 \mathrm{DPI})$ 

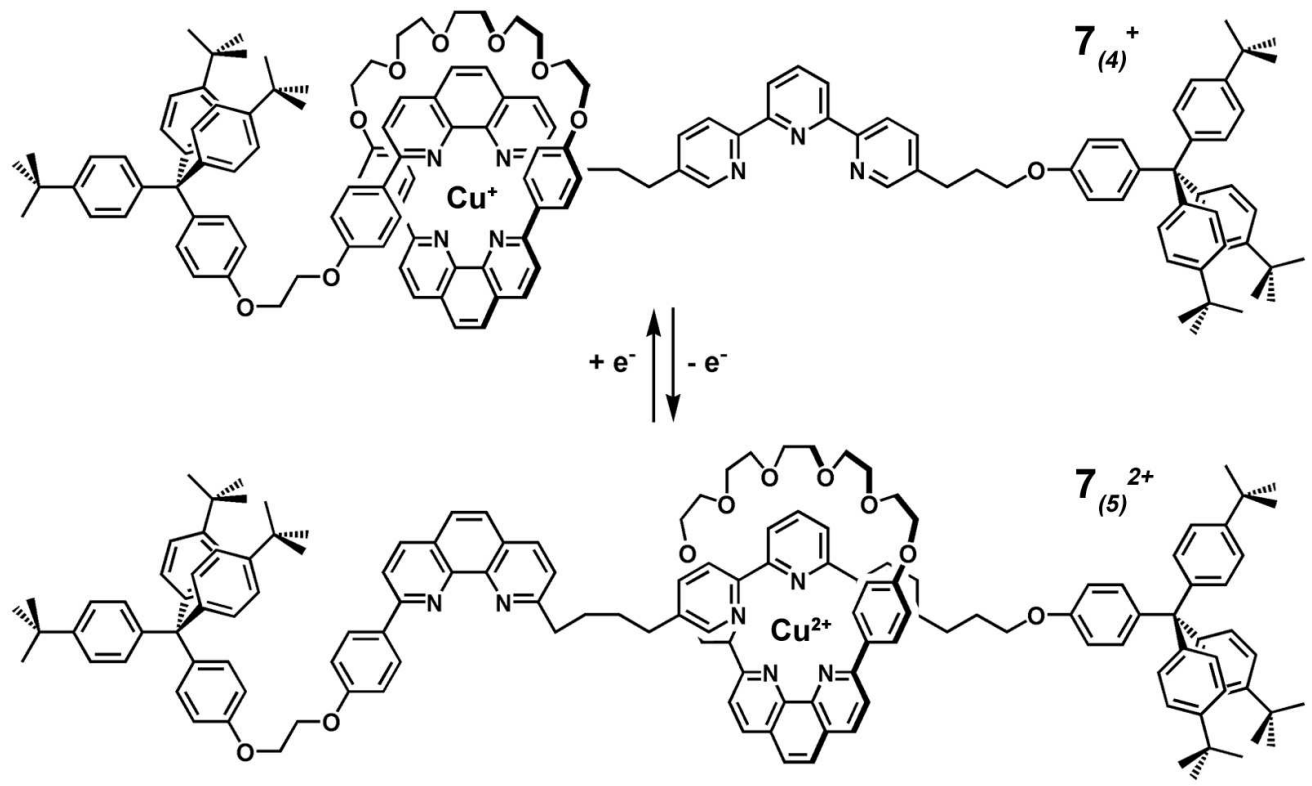

Two-station molecular shuttle with a relatively flexible molecular axis containing a dpp-station and a terpyridine-station and a 30-membered macrocycle incorporating a dpp chelate. $89 \times 54 \mathrm{~mm}(450 \times 450 \mathrm{DPI})$ 

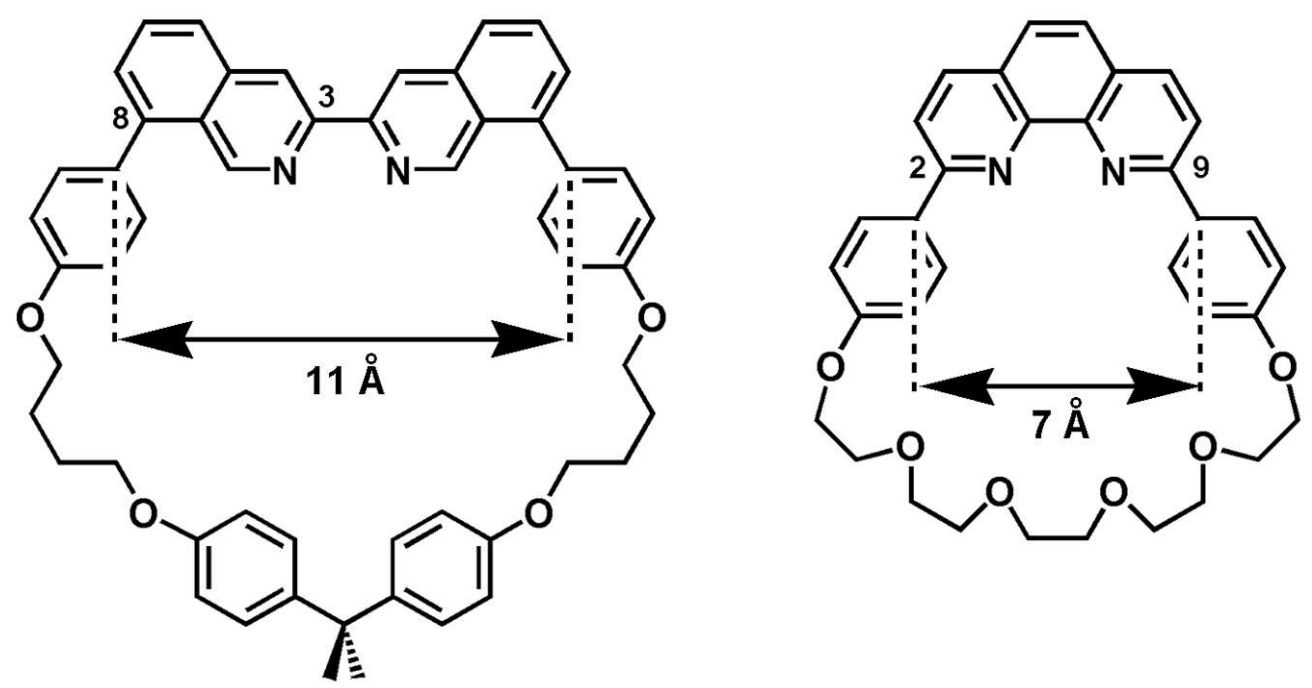

A 39-membered macrocycle with the dpbiiq ligand motif and a 30-membered macrocycle with the dpp fragment.

$85 \times 51 \mathrm{~mm}(400 \times 400$ DPI $)$ 

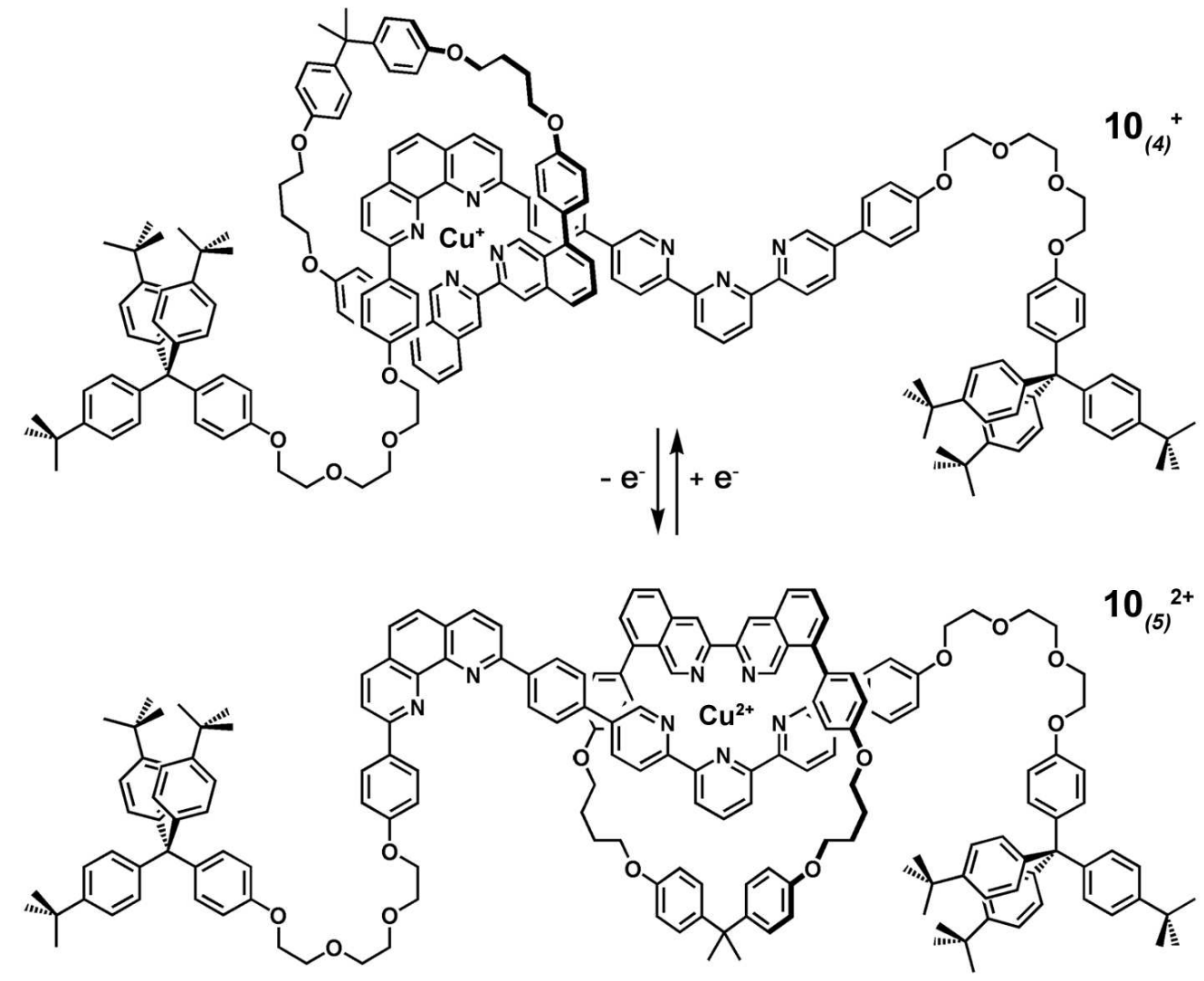

A copper-based molecular shuttle with a rigid axis and a sterically non-hindering macrocycle. $89 \times 76 \mathrm{~mm}(400 \times 400 \mathrm{DPI})$ 
1

2

3

4

5

6

7

8

9

10

11

12

13

14

15

16

17

18

19

20

21

22

23

24

25

26

27

28

29

30

31

32

33

34

35

36

37

38

39

40

41

42

43

44

45

46

47

48

49

50

51

52

53

54

55

56

57

58

59

60

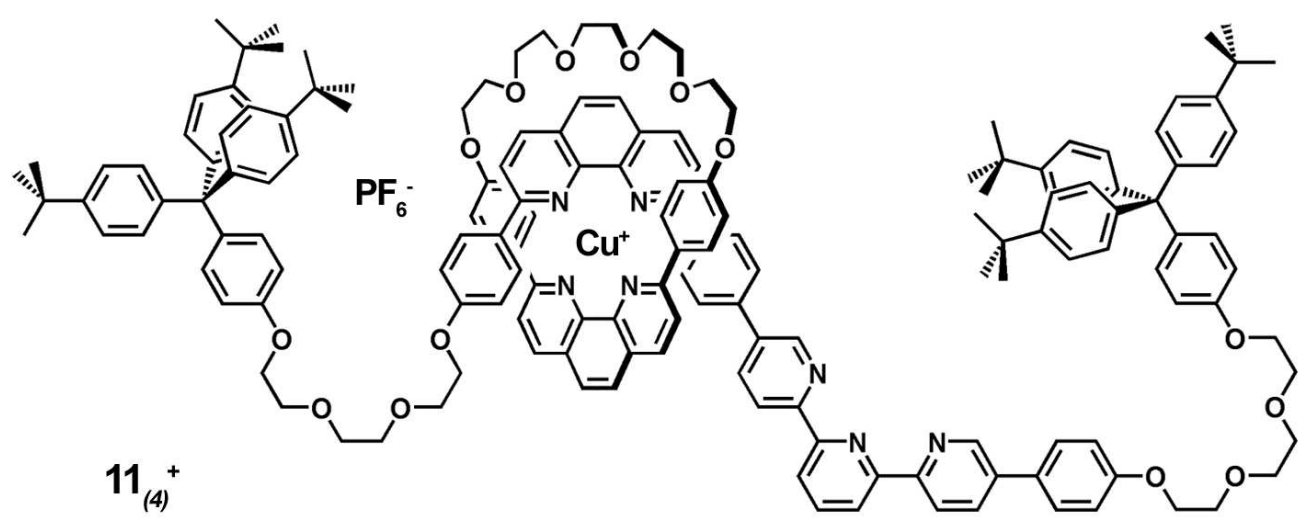

A molecular shuttle comprised of the same rigid axis as the shuttle from Scheme 6, but with the smaller macrocycle 9 instead of the sterically non-hindering macrocycle 8. $89 \times 35 \mathrm{~mm}(400 \times 400 \mathrm{DPI})$ 

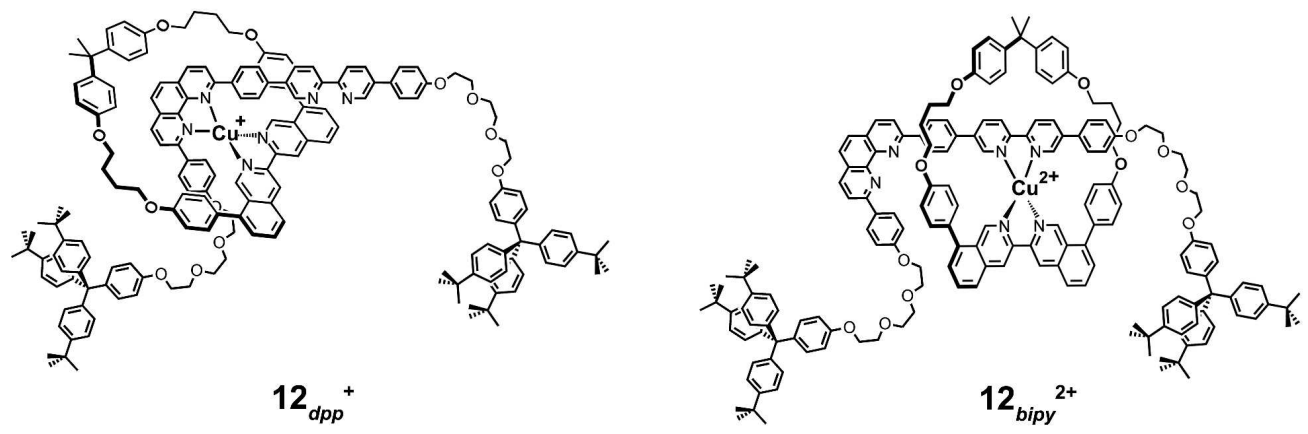

A phenanthroline-bipyridine two-station shuttle in its two different forms $12 \mathrm{dpp}+$ and 12 bipy $2+$; the subscripts dpp and bipy indicate the position of the mobile ring (macrocycle 8 ) on the molecular axis.

$333 \times 111 \mathrm{~mm}(300 \times 300 \mathrm{DPI})$ 

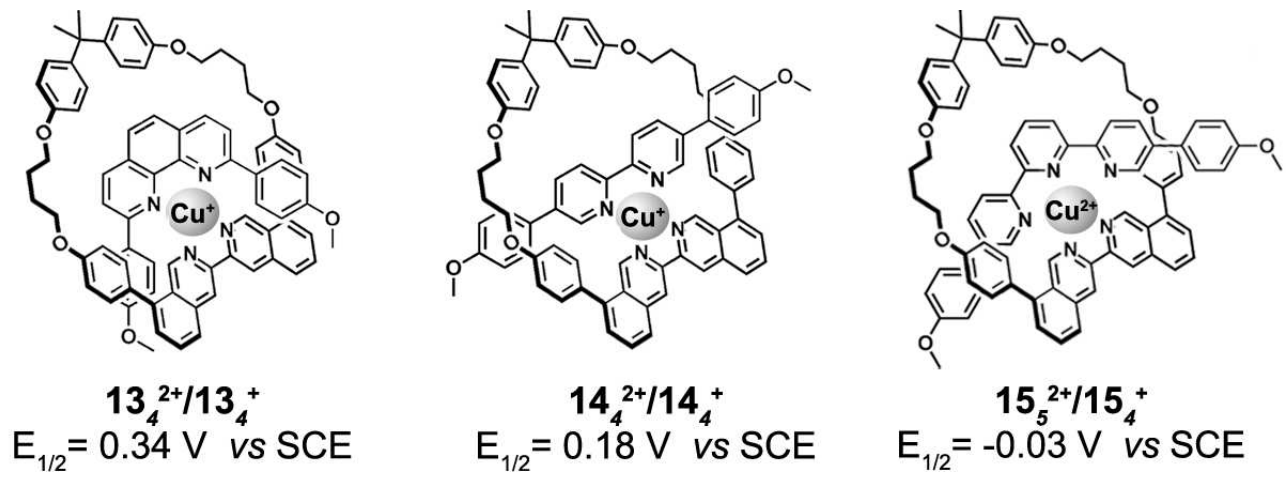

$15_{5}{ }^{2+} / 15_{4}^{+}$ $E_{1 / 2}=-0.03 \mathrm{~V}$ vs SCE

Reference complexes for electrochemical investigations. $103 \times 36 \mathrm{~mm}(300 \times 300$ DPI $)$ 


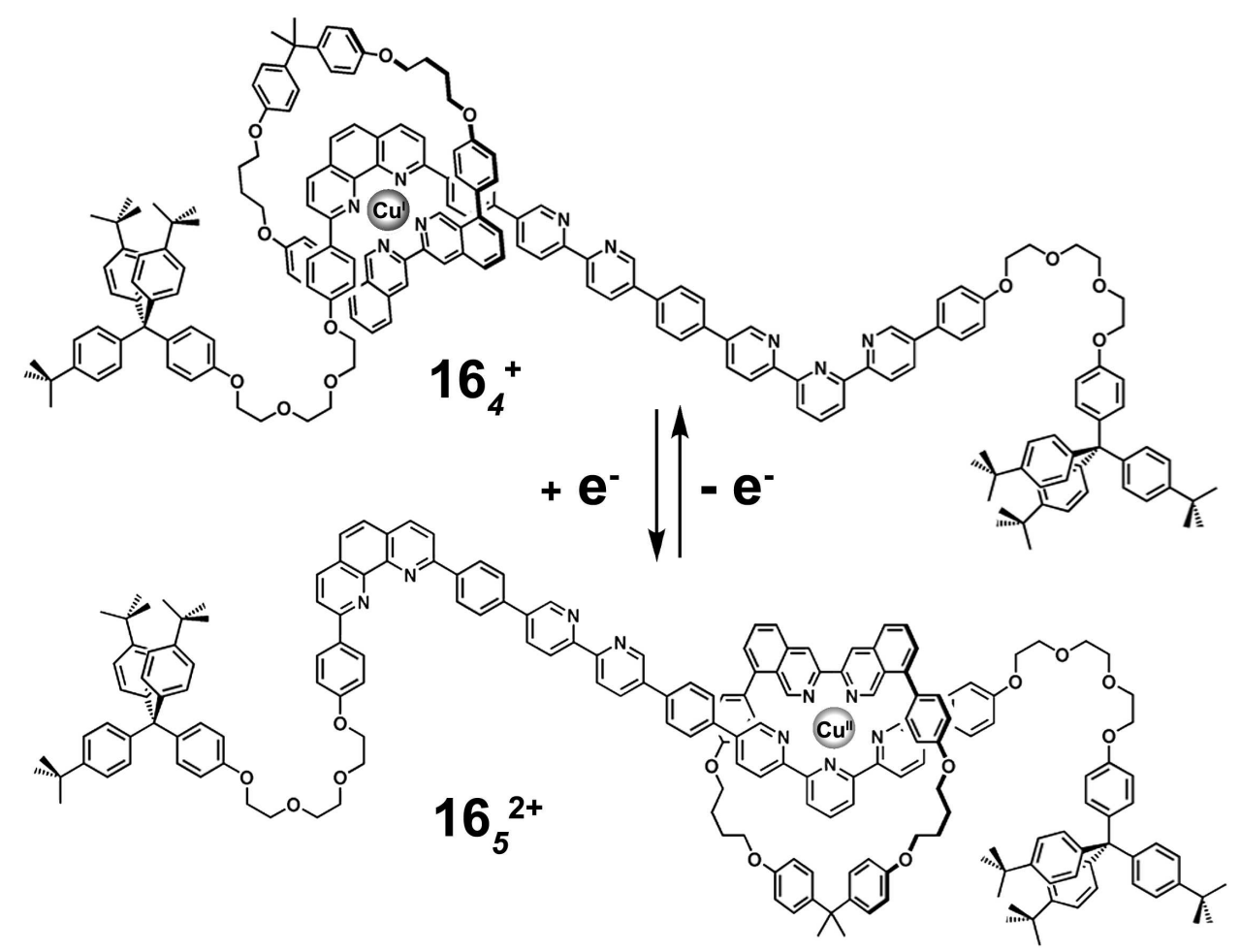

Three-station rotaxane 16 containing dpp, bipy and terpy stations on the molecular axis and dpbiiqbased macrocycle 8 . The subscripts indicate the coordination numbers of the copper center. $201 \times 150 \mathrm{~mm}(300 \times 300 \mathrm{DPI})$ 

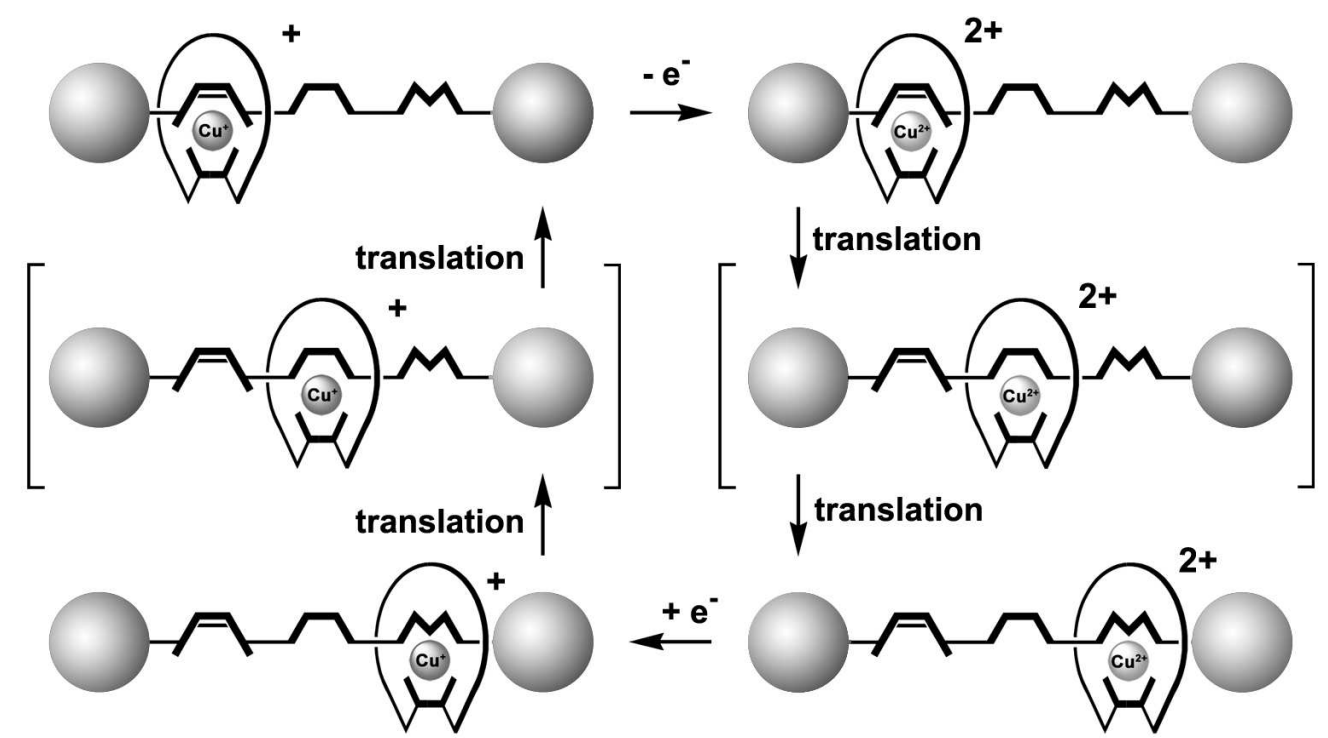

$$
\mathscr{A}=\mathrm{dpp} \quad M=\text { bipy } M=\text { terpy } V=\text { dpbiiq }
$$

Operating principle of the molecular three-station shuttle 16 from Scheme 10. $193 \times 127 \mathrm{~mm}(200 \times 200$ DPI $)$ 